\title{
Job Search and Job Finding in a Period of Mass Unemployment: \\ Evidence from High-Frequency Longitudinal Data
}

\author{
Alan B. Krueger \\ Princeton University \\ and \\ Andreas Mueller* \\ Stockholm University
}

January 16, 2011

\begin{abstract}
This paper presents findings from a survey of 6,025 unemployed workers who were interviewed every week for up to 24 weeks in the fall of 2009 and spring of 2010. Our main findings are: (1) the amount of time devoted to job search declines sharply over the spell of unemployment; (2) the self-reported reservation wage predicts whether a job offer is accepted or rejected; (3) the reservation wage is remarkably stable over the course of unemployment for most workers, with the notable exception of workers who are over age 50 and those who had nontrivial savings at the start of the study; (4) many workers who seek full-time work will accept a part-time job that offers a wage below their reservation wage; and (5) the amount of time devoted to job search and the reservation wage help predict early exits from Unemployment Insurance (UI).
\end{abstract}

*We thank Ed Freeland for invaluable assistance designing and implementing our survey, Yasamin Miller and her team for implementing the web survey, Doug Mills for computer programming assistance, and the Princeton University Industrial Relations Section and Woodrow Wilson School for financial support. We thank Orley Ashenfelter, David Card, Larry Katz and Rob Shimer for helpful comments. This research was conducted under the terms of a Memorandum of Understanding with the New Jersey Department of Labor and Workforce Development, and we are grateful for their assistance and cooperation. The authors are solely responsible for all views expressed in the paper and any errors. 


\section{Introduction}

For the first time since the early 1980s, mass unemployment is a problem in the United States. The unemployment rate reached 10.1 percent in October 2009, more than double its rate a year and half earlier. In addition, nearly half of the unemployed were out of work for 27 weeks or longer in mid 2010. Extended unemployment carries with it the risk that many of those out of work will lose relevant skills and become discouraged from looking for work, raising the specter of hysteresis and permanently higher joblessness. This paper provides evidence on the job search process, the effectiveness of job search activities, and the decision to accept a job if an offer is received using new survey data for a large sample of unemployed workers collected in the fall of 2009 and spring of 2010. We devote particular attention to measuring how job search activity and the reservation wage vary over the course of unemployment for a given set of individuals.

Our study is distinguished from past work by the use of high-frequency longitudinal data. Specifically, we designed and implemented a large-scale weekly survey of Unemployment Insurance (UI) recipients in New Jersey. More than 6,000 unemployed workers participated in the survey for up to 12 weeks, and the long-term unemployed were surveyed for an additional 12 weeks. A total of 39,201 weekly interviews were completed. We also have restricted access to administrative data from the UI system, which is important given high rates of nonresponse. New Jersey's unemployment rate closely mirrored the national average in 2009 and 2010, so the results shed light on job search behavior in the worst labor market environment in decades.

We focus on the two key variables from standard job search models: (1) the amount of time devoted to searching for a job each day; and (2) the lowest wage that individuals would be willing to accept if they receive a job offer (i.e., the reservation wage). We also examine the 
relationship between job search and the likelihood of receiving a job offer and exiting UI, and the relationship between the stated reservation wage and the decision to accept a job offer. Our main conclusions are: (1) job search declines steeply over the spell of unemployment; (2) after a period of rapidly rising unemployment, workers who lost their jobs at different times are strikingly different, and comparisons across cohorts that lost their jobs at different times are prone to bias; (3) a comparison of whether the self-reported reservation wage is below or above the offered wage is a reliable predictor of acceptance or rejection of a job offer; (4) in contrast to job search activities, the reservation wage is remarkably stable over the course of unemployment for most workers, with the notable exception of workers who are over age 50 and those who had a bank account with at least $\$ 10,000$ at the start of our study; (5) relatively many workers who are seeking full-time work will accept a part-time job that offers a wage below their reservation wage, perhaps because part-time work is considered a transition to a higher paying full-time job; (6) the amount of time devoted to job search and the reservation wage help to predict early exits from UI; and (7) the choice of job search activities and amount of search time do not bear a straightforward relationship with the likelihood of receiving a job offer but they do predict early exits from UI, although unmeasured characteristics of workers could distort the underlying relationships.

In the next section we describe the data used in our study and assess the effect of survey nonresponse. We also summarize relevant features of UI, as it was in effect in the fall of 2009 and spring of 2010. Sections 3 and 4 examine patterns of job search behavior and the reservation wage over the spell of unemployment, respectively. Section 5 considers the relationship between job search activities and the incidence of job offers and early exits from UI, and Section 6 models whether a job offer is accepted or rejected. Section 7 concludes the paper. 


\section{Description of the Survey and Unemployment Insurance}

In early October 2009, the Princeton University Survey Research Center (PSRC) obtained a complete list of the roughly 360,000 individuals receiving UI benefits in New Jersey as of September 28, 2009. The data were subjected to a stratified random sampling procedure to obtain a sample of $63,813 \mathrm{UI}$ recipients. The strata consisted of duration of unemployment intervals by the availability of an email address. ${ }^{1}$ The sampled individuals were invited to participate in an online survey for a period of 12 weeks, with weekly interviews on their job search activities, time use, reservation wages, job offers, food consumption and other variables. Participants were paid $\$ 20$ to $\$ 40$ for participating in the survey. In addition, for those who were unemployed for 60 weeks or longer at the start of the survey, interviewing took place for an additional 12 weeks, for a total of 24 weeks.

The questionnaire consisted of two parts: an entry survey in the first week of the survey with demographic, income and wealth questions, and a shorter follow-up survey each week that focused on job search activities, the reservation wage, and receipt of job offers. ${ }^{2}$ The appendix provides a detailed description of the survey and questionnaire.

One issue of concern is that the response rate was low. Only 10 percent of sampled individuals who were contacted participated in the entry wave of the survey, and respondents in the entry survey only participated in about 40 percent of the weekly follow-up surveys. Fortunately, the administrative data file contains a rich set of demographic variables that can be used to create sample weights to adjust for nonresponse, and the characteristics of respondents can be compared to the universe along a number of relevant dimensions, including pre-

\footnotetext{
${ }^{1}$ Long-term unemployed workers and those with email addresses on file were oversampled.

${ }^{2}$ The survey questionnaires can be downloaded at http://www.princeton.edu/ psrc/NJWS/ENTRY.pdf and http://www.princeton.edu/ psrc/NJWS/WEEKLY.pdf.
} 
unemployment earnings. ${ }^{3}$ In addition, we were able to match information on the duration of benefit receipt as of April 2010 for the entire sample frame, so we can compare the UI exit rate for the sample frame and for the respondents.

Table 2.1 summarizes the characteristics of the universe of UI recipients, sample frame, and respondents. In addition, the last two columns report estimates that adjust for strata weights and nonresponse weights. Compared with the universe of UI recipients, the respondents were more likely to be college graduates (41\% vs. $19 \%)$ and female (52\% vs. $45 \%)$, and to have had higher earnings in the base period $(\$ 48,994$ vs. $\$ 35,335)$. The weighted sample and universe are very similar in terms of demographic characteristics, however, which is not entirely surprising given that demographic variables were used to create nonresponse weights. It is more reassuring that the weighted average earnings in the base year $(\$ 37,960)$ is reasonably close to average earnings in the base year in the universe, because earnings were not used to create weights. In addition, the industry composition of the weighted respondents is similar to the universe, although construction workers are somewhat underrepresented among the respondents. Finally, weeks of UI paid are slightly lower for the weighted respondents than for the universe, but similar to those in the weighted stratified sample. As a whole, the weighted survey participants and the universe appear to be similar along many dimensions despite the low response rate.

Additional evidence suggesting that the low response rate has not significantly skewed the sample is in Figure 2.1, which shows the Kaplan-Meier nonparametric UI exit rate by duration of unemployment measured by weeks of UI paid. The hazard rates are reported separately for the (weighted) stratified sample frame and respondents. The hazard rate at duration

\footnotetext{
${ }^{3}$ Sample weights were derived by estimating a logit for participation in the survey each week, and predictors were the demographic variables listed in the bottom part of Table 1. It was necessary to weight the sample frame to reflect the universe as well because of oversampling of certain strata. See the appendix for more details on the construction of both sets of weights.
} 
$t$ is defined as the fraction of UI spells ongoing at the start of week $t$ that ended during the week t. A spell could end because a worker found a job or was no longer eligible for benefits. Spells were considered censored if the date of the last UI payment was in the week of April 30, 2010 or later, the date we received the updated administrative data on weeks of UI paid. ${ }^{4}$ Figure 2.1 shows that the weekly exit rate for the respondents closely tracks that of the sample frame, and is within the $95 \%$ confidence interval at almost all durations. A notable exception, however, occurs in the first couple of weeks, when the hazard rate for the sample frame is around twice that of the respondents. This disparity probably arises because some workers had found employment shortly after they filed their UI claim and thus were unlikely to respond to our survey. ${ }^{5}$ Over most durations, however, the hazard rates are similar.

Figure 2.1 displays the typical pattern of a declining hazard at the beginning of a spell of unemployment, and then a roughly constant hazard rate thereafter. The hazard rate profile is flatter than has been found in other studies, however (e.g., Katz and Meyer, 1990). In addition, the weekly exit rate is lower than has been found in previous work. These differences probably reflect the weak job market in late 2009 and the low incidence of temporary layoffs.

Figure 2.1 also shows notable spikes in the hazard rate at week 26 and week 51 . The reason for the spike at week 26 is that the eligibility requirements for extended benefits are

\footnotetext{
${ }^{4}$ One minor complication that arises in our data is that the universe consists of individuals who were unemployed at the end of September 2009, and thus includes some unemployed workers who filed UI claims as early as May 2006. However, those who filed claims in May 2006 or later but subsequently exited UI are not included in our universe file. Typically, studies that analyze UI exit rates (e.g., Moffitt, 1985 or Meyer, 1990) sample from the newly unemployed (the inflow), not the stock of unemployed, and thus do not encounter this issue. The sample truncation problem can be easily addressed by only using information on UI spell duration from the start of the study and thereafter. In other words, UI spells were included in the number of ongoing spells only for durations equal to or greater than the duration at the beginning of the study. For example, if an unemployed worker had 60 weeks of UI paid at the start of the study, he or she was not included in the number of ongoing spells in weeks 1-59, but only from week 60 and onwards. Including this person in the number of ongoing spells before week 60 - without data on unemployed workers who filed claims at the same time but exited unemployment before week 60 - would severely downward bias the hazard at lower durations.

${ }^{5}$ Note that there was a 2-3 week gap between the date the data were extracted and the date invitations to participate in the survey were sent out.
} 
slightly more stringent than the requirements for regular benefits, which for most workers last 26 weeks. $^{6}$ Therefore, a small number of UI recipients exhausted benefits at week 26 . The spike at week 51 arises because workers are tested for continued eligibility for extended UI benefits at the end of each benefit year (52 weeks after the UI claim was filed). ${ }^{7}$ We do not see a spike in the job finding rate at either 26 or 51 weeks in our survey data, so the spikes most likely result from these program requirements. Regardless of the reason for the spikes, the weighted sample appears to have similar prospects of leaving UI as the broader sample frame that we sought to interview, suggesting that nonresponse was fairly random with respect to job market prospects.

\subsection{Unemployment Insurance in New Jersey in 2009-10}

New Jersey has one of the more generous UI systems in the U.S. The benefit is 60 percent of previous earnings, up to a maximum weekly benefit amount of $\$ 584$ in 2009 . $^{8}$ The maximum duration of regular UI benefits varies between one and 26 weeks, depending on how many weeks the claimant worked in the base year. Most unemployed workers in New Jersey qualify for the maximum duration of regular benefits: in our data, 87 percent qualified for 26 weeks of regular benefits and only 3 percent qualified for fewer than 20 weeks.

\footnotetext{
${ }^{6}$ The earnings requirement for regular UI benefits in 2009 was 20 base weeks of work (earning a minimum of $\$ 143$ each week) or total earnings of at least 1,000 times the state minimum wage (\$7.25 per hour as of July 2009) in the base year. The earnings requirement for extended benefits (both the federal and the state program) is 20 base weeks of work (earning a minimum of $\$ 143$ each week) or earning 40 times the weekly benefit amount on their UI claim. This implies that unemployed workers who qualified for regular benefits because of total earnings in excess of $\$ 7,300$, but had less than 20 weeks of base weeks worked, may not qualify for extended benefits if the weekly benefit amount on the regular UI claim was high (e.g., with earnings of $\$ 7,300$, the weekly benefit amount on the regular claim had to be lower than $\$ 182.5$ to meet the extended benefit earnings requirement).

${ }^{7}$ One of the requirements for eligibility for extended UI benefits is that workers are not eligible for a new claim of regular UI benefits. A small number of individuals qualify for a new regular UI claim because earnings from the initial base year usually exclude the quarter just before the start of the UI spell but that quarter and part-time earnings during the initial unemployment spell contribute towards eligibility for a new regular claim. The spike at 51 weeks is probably because the benefit rate drops substantially when unemployed workers qualify for a new regular claim (because of lower earnings in the new base year) and thus individuals may not find it worthwhile to file a new regular UI claim.

${ }^{8}$ Unemployed workers can also qualify for a dependents' allowance for up to three dependents (children under the age of 19 and a spouse). The allowance is $7 \%$ of the weekly benefit for the first dependent and $4 \%$ for the second and the third dependent. Note that the maximum weekly benefit is not adjusted for dependents.
} 
In New Jersey, UI recipients are allowed to work on part time jobs while receiving benefits. Earnings from part time jobs are deducted from the benefit amount, with an earnings disregard of $\$ 5$ or $20 \%$ of the weekly benefit, whichever is greater. This implies that UI recipients who work part time can keep weekly earnings of up to $20 \%$ of the weekly benefit amount; any earnings in excess of that is deducted from the weekly benefit. Thus, those who earn more than $120 \%$ of their weekly benefit no longer qualify for UI benefits. A worker who works part time during a period of unemployment may draw benefits for a longer period than the maximum duration for an otherwise comparable beneficiary who does not work at all. The reason is that the state specifies a maximum dollar amount that can be received for a given UI claim (the maximum benefit amount), and those who work part time can receive benefits for a longer period of time because their weekly benefit amount is reduced.

The duration of UI benefits is affected by federal extensions as well as state policy. In June 2008 the federal government established the Emergency Unemployment Compensation (EUC) program, which entitled UI recipients to an additional 13 weeks of extended UI benefits in all U.S. states, and in November 2008 EUC was extended to 33 weeks in high unemployment states. The American Recovery and Reinvestment Act (ARRA) in February 2009 extended the expiration date of EUC to December 31, 2009 and raised weekly benefits by $\$ 25$. In addition to the federal extension, New Jersey activated the state Extended Benefits (EB) program on March 15, 2009, which initially provided for an additional 13 weeks of UI benefits, and then for 20 weeks on May 3, 2009.

When interviewing for our survey commenced on October 13, 2009, UI recipients in New Jersey were eligible for up to 79 weeks of benefits, counting regular benefits, EUC and 
EB. ${ }^{9}$ On November 6, 2009, the federal government increased EUC benefits by an additional 20 weeks, increasing the maximum duration in New Jersey from 79 to 99 weeks. The increase to 99 weeks probably came as a surprise to many workers. This extension was retroactive in the sense that workers who had exhausted the 79 weeks of benefits that they were eligible for before the extension to 99 weeks became eligible for another 20 weeks of benefits. The extension was effective in New Jersey as of November 8, 2009.

We refer to the 640 individuals in our sample who had exhausted benefits prior to November $8^{\text {th }}$ and then qualified for the 20-week extension as having "lapsed benefit receipt" in the interim period when they were not receiving benefits. ${ }^{10}$ (Some 1,264 weekly surveys were completed during periods when benefits were lapsed.) We refer to the 224 individuals in our sample who reached 99 weeks of paid benefits and then were no longer eligible for benefits as having "exhausted benefits" after week 99. (Some 346 weekly interviews were completed by individuals after they exhausted benefits.) And we can estimate the effect of the availability of an additional 20 weeks of EUC in our sample by including a dummy variable indicating weeks after the extension took effect on November 8, 2009.

\section{Job Search over the Spell of Unemployment}

In a standard job search model with stationarity (e.g., Mortensen, 1977), the amount of time and effort that job seekers devote to searching for a job should be constant or rising over the spell of unemployment, as benefits are exhausted and assets are run down. We provide the first test of this prediction with longitudinal data. We have two measures of job search: information from

\footnotetext{
${ }^{9}$ Note that the weekly benefit amount on EUC as well as the EB program was the same as for regular benefits, and the maximum potential duration was less than 79 weeks if a worker qualified for less than 26 weeks of regular benefits. The potential duration of extended benefits is nearly proportional to the potential duration of regular UI benefits. The exact formulas can be found on http://lwd.state.nj.us/labor/ui/content/ui_benefit_extensions .html. ${ }^{10}$ For claimants who continued to certify their status, benefits during the lapsed period were paid in a lump sum after benefits resumed.
} 
the time diary for the day preceding the interview and responses to questions about time spent on various search activities in the preceding week.

According to the time diary data, the average worker spent 70 minutes searching for a job on weekdays, and 65 minutes over all days. ${ }^{11}$ This is close to the amount of time that unemployed workers who appear eligible for UI reported searching for a job in the 2009 American Time Use Survey (ATUS).

The weekly recall questions on job search activities - which asked for the amount of time spent on eleven categories of search activities in the last week - imply that workers spend significantly more time searching for a job. The average amount of time searching was 11.5 hours per week, or 100 minutes per day. It is unclear whether the week-long recall questions lead respondents to exaggerate their search time or whether listing the specific activities results in more accurate recall. As a consequence, we analyze both measures.

Figures 3.1a and 3.1b display average search time from the diary survey and weekly recall questions, respectively, broken down by cohort, where cohorts are defined by the duration of unemployment at the start of our survey. ${ }^{12}$ Both graphs show the same pattern: declining search time over the duration of the spell of unemployment for each cohort. It is curious, however, that the search-time profiles are virtually parallel lines, and, with the exception of the very long-term unemployed, that average search time at the end of one cohort's data does not overlap with the beginning of the next cohort's. We return to this feature of the data at the end of this section.

Table 3.1a.and 3.1b present regression estimates where the dependent variable is time spent searching for a job per day, measured by the time diary and weekly recall questions, respectively. The key explanatory variable is duration of benefit receipt, and other explanatory variables

\footnotetext{
${ }^{11}$ See the Appendix for a detailed description of data coding issues.

${ }^{12}$ Individuals are dropped from the sample once they accept a job offer.
} 
include age, education, sex, race, ethnicity, the log benefit and the log of the previous wage. The first column is estimated using only the entry-week survey, so there is just one observation per respondent. These estimates correspond to the cross sectional literature that has compared search time across workers with different durations of unemployment (e.g., Krueger and Mueller, 2010). The rest of the columns are estimated with the pooled sample of respondents, using all of their weekly responses. The third and fourth columns control for unrestricted person fixed effects, so the only source of variability in the duration variable is due to within-person changes in unemployment duration.

The table highlights the importance of analyzing longitudinal data. Duration of unemployment has a positive association with search time in the cross sectional models using either measure (and the relationship is significant in Table 3a), while it has a negative, statistically significant and sizable association in the fixed effects models, which exploit the longitudinal data. It is clear from Figures 3.1a and 3.1b that a line fit through the cohorts would have a different slope than the typical line fit within each cohort; the regressions bear this out.

The sharp decline in search time over the spell of unemployment is noteworthy. In the model in column 3 of Table 3a, for example, daily search time falls by 30 minutes over a 12 week period, about a third of the average search time of those with new spells of unemployment. This pace of decline could not be sustained for very long without hitting the zero bound. From Figures 3.1a and 3.1b, however, it is apparent that the gradient becomes flatter at long durations of unemployment.

Using the time diary data, we have looked at which activities increase while search time decreases over a spell of unemployment. Interestingly, the only activity that significantly increases with duration of unemployment is sleep. And, even more precisely, sleep in the 
morning hours tends to rise. An analysis of the time diaries indicates that half of job search activity takes place between $7 \mathrm{AM}$ and $1 \mathrm{PM}$.

We have also looked separately at participation in any job search at all on the reference day and the amount of time spent searching conditional on some time spent searching. Both participation in search, and the amount of search time conditional on searching, decline with the duration of unemployment. Moreover, this finding holds in both the time diary data and weekly recall data.

The model in column 4 of Tables 3.1a and $3.1 \mathrm{~b}$ include additional variables relating to UI benefit receipt. Specifically, we include dummy variables indicating weeks when an individual's UI benefits lapsed or were exhausted, and a dummy variable indicating observations after November 8th, 2009, the date when the maximum duration of benefit receipt was extended from 79 to 99 weeks. Adding these variables reduces the magnitude of the coefficient on unemployment duration by about a third, but it is still negative an highly statistically significant. Moreover, if we estimate the model in Column 3 separately using data before or after the November $8^{\text {th }}$ extension, we find that search time declines with unemployment duration in both samples. Thus, the decline in search activity over the spell of unemployment seems to be robust to efforts to take account of the extension of benefits in early November.

We do not find statistically significant evidence of a change in search time during periods in which benefits were lapsed or were exhausted for either measure of search time. The postNovember $8^{\text {th }}$ EUC extension indicator variable is highly statistically significant, although the effect of the extension is difficult to interpret, as it could reflect nonlinear effects of duration. The effect of the post-November $8^{\text {th }}$ dummy variable is larger and more robust to changes in the functional form of unemployment duration in the diary data on job search. If we add the square 
of the duration of unemployment to the model in column 4 , for example, the coefficient on the post-November $8^{\text {th }}$ dummy variable in Table $3.1 \mathrm{a}$ is still -14.5 minutes with a t-ratio of 4.2 , while it falls from 11.8 minutes $(\mathrm{t}=3.2)$ to 5.7 minutes $(\mathrm{t}=1.5)$ with the weekly recall search data in Table 3.1b. Thus, estimates of the effect of the extension on job search time are dependent on the functional form of unemployment duration and the exact measure of job search time.

Turning to the other variables in Tables 3.1a and 3.b, we find that the log of the benefit and of the wage have their expected signs. The benefit-search elasticity at the mean search time over all observations is around -0.3 with either measure of search time. This is substantially smaller than the corresponding elasticity in Krueger and Mueller (2010), perhaps because of the higher unemployment rate in the period under study in this paper or the different source of benefit variability. The wage elasticity ranges from 0.2 to 0.4 in the model in column 2 . The identification of the wage and benefit elasticities, however, depends on nonlinearities in the benefit formula, so these estimates should not be taken too literally.

\subsection{Job Search Methods}

Figure 3.2 displays the proportion of job search time in the past week spent on various methods. Almost two thirds of job search time is spent looking at ads, placing or answering ads and sending out applications. Contacting friends and relatives, which has been found to be a highly effective job search method in past studies (e.g., Holzer, 1988; Granoveter, 1974), accounts for 9 percent of search time. Only 3 percent of time is spent on job interviews.

Table 3.2 reports regression results where the dependent variable is the amount of time devoted to each search activity per day and the explanatory variables include the duration of unemployment and fixed person effects. (The model corresponds to column 3 of Table 3.1b.) With the exception of contacting a public employment agency, the other search activities decline 
with the duration of unemployment. Interestingly, if one scales the coefficients by the average time devoted to the method, the activities decline roughly in proportion to their average time. Thus, the pie chart in Figure 3.2 looks fairly similar if one uses the first week or 12th week of the observed spell of unemployment.

\subsection{Duration, Calendar Time and Cohort Effects}

We have implicitly discussed changes in job search behavior associated with changes in unemployment duration for individuals or cohorts as if they were a result of duration itself. However, an alternative interpretation is that what appears to be a duration effect is actually the effect of calendar time since, for a given cohort indexed by time of job loss, increases in duration necessarily correspond to movements in calendar time. For example, because our survey began in October, it is possible that evolving seasonal or business cycle conditions led to a decline in job search as we moved from October to November and November to December. If job search is weaker in November because of Thanksgiving, and weaker still in December because of Christmas, for instance, we might observe a pattern like those in Figure 3.1a and 3.1b.

Although one can never separately identify duration and calendar time effects for given cohorts, we think a range of evidence suggests that seasonal, holiday and business cycle effects are not responsible for the observed decline in search time over the spell of unemployment in our data. First, if we drop last two weeks of November and December to avoid the effects of Thanksgiving and Christmas, the coefficient on duration in column (3) of Table 3.1a and 3.1b hardly changes. Second, in an effort to examine the effect of seasonal employment, we dropped construction workers, who tend to have highly seasonal employment in New Jersey, and found a similar slope. Perhaps more importantly, we looked separately at education and health care industry workers, who have a steady demand for their services, and again found that job search 
declined with unemployment duration. Third, we compared the gradient for men and married women, on the theory that married women have a greater opportunity cost of time around Thanksgiving and Christmas, and found that search time declined with duration for both groups at almost an equal rate.

Additional evidence that seasonal factors are not at work comes from the ATUS. In particular, we find that from 2003 to 2009 , job search time by the unemployed tended to rise from October to November, fall in December, and rise in January. So there is no evidence of a monotonically declining pattern over the months. Likewise, the BLS seasonal adjustment factor for the unemployment rate in New Jersey is similar in October, November and December, which indicates relatively little seasonal shifts in unemployment. We also do not find a decline in job offers or UI exits in November and December in our data. Finally, the unemployment rate was fairly stable in New Jersey in the last quarter of 2009 and first quarter of 2010, suggesting that swings in the business cycle were not important.

While we find little evidence of temporal effects that would cause the downward search profiles in Figures 3.1a and 3.1b, we do find some evidence that the cohorts that became displaced at different times are very different. Figure 3.3, for example, shows average earnings in the base year by cohort. ${ }^{13}$ Among UI recipients, those who were laid off more recently and hence have shorter durations, average earnings prior to displacement were significant lower. For example, average earnings in the base year for those who were unemployed 0-2 weeks at the start of our study were approximately $\$ 36,000$, compared with $\$ 38,000$ for those unemployed 10-12 weeks and \$42,000 for those unemployed 20-22 weeks. Moreover, the cohorts do not overlap in terms of earnings -- or other characteristics such as industry and education -- when we

\footnotetext{
${ }^{13}$ This figure is based on administrative earnings data for all of the initial respondents, so attrition is not an issue. Individuals are dropped from the sample once they exit the UI program.
} 
compare groups with the same duration of unemployment at different calendar times. The cohorts based on duration of unemployment at a fixed calendar date are different because workers in different industries and skill groups were laid off at different times. Thus, at least in this period when unemployment had been rising rapidly for the preceding year and a half, comparing workers who have been unemployed for different lengths of time at a point in time can be misleading because of differences in background characteristics across cohorts. The cohorts with lower earnings, for example, would be expected to search less, and this could at least partially explain why search time at is not lower for the cohorts that were unemployed longer at the beginning of our survey.

\section{Reservation Wage over the Spell of Unemployment}

As workers exhaust their UI benefits and assets, the reservation wage would be expected to decline. To test this hypothesis, each week we asked respondents for the lowest wage offer that they would accept. Our questionnaire used essentially the same language that was used to elicit the reservation wage in the May 1976 Current Population Survey (CPS), which was analyzed by Feldstein and Poterba (1984). The previous wage is from the administrative records, and previous work hours are from the entry survey.

We start by comparing our results to Feldstein and Poterba's. Table 4.1 reports the average ratio of the reservation wage to the pre-unemployment wage. ${ }^{14}$ The first two rows are taken directly from Feldstein and Poterba, who found that, on average, the reservation wage is slightly higher than the previous wage, and that the reservation wage is only slightly lower among

\footnotetext{
14 The reservation wage data were trimmed in essentially the same manner as in Feldstein and Poterba. In addition, we dropped a handful of cases in which the worker received the maximum weekly UI benefit but reported a low weekly wage, because the weekly wage was probably misreported.
} 
workers with longer durations of unemployment. The second row, which shows their results for job losers, is probably more comparable to our sample of UI recipients.

The third row reports the average reservation wage ratio using just the entry-week survey responses to compare with the cross sectional CPS data. The results are remarkably similar, although the economic environments were very different in the two time periods. (The national unemployment rate in May 1976 was 7.4 percent, down from 9.0 percent a year earlier.) Across all durations, the reservation wage ratio is essentially equal to the previous wage, on average, in both samples. Nonetheless, there is substantial variability across workers. The 25 th percentile reservation wage ratio in our sample is 0.70 , the median is 0.91 , and the 75 th percentile is 1.17 . In 6.7 percent of cases, the reservation wage is below the weekly UI benefit.

In our cross sectional data, the reservation wage ratio falls by 10 percentage points comparing workers with less than 5 weeks of unemployment to those with 50 or more weeks of unemployment. The corresponding figure in Feldstein and Poterba is 9 points.

The last row of Table 4.1 utilizes the longitudinal data. In particular, we regressed the reservation wage ratio on unemployment duration and individual fixed effects, so we can examine how much the reservation wage falls as unemployment duration increases for a given set of job seekers. ${ }^{15}$ The longitudinal estimates point to an even more gradual decline in the reservation wage with unemployment duration than Feldstein and Poterba found.

The correlation in the reservation wage in adjacent weeks was 0.96 , so at the individual level the self-reported reservation was stable as well. (For reference, the correlation in earnings in a given period reported by individuals at different times is typically around 0.90; see Bound and Krueger, 1991.)

\footnotetext{
${ }^{15}$ Specifically, we used the fixed effects estimates from column 3 of Table 4.2 and used the midpoint of each category to predict the log reservation wage ratio, and then exponentiated.
} 
The top panel of Figure 4.1 shows the average reservation wage ratio by duration of unemployment for each of the sampled cohorts. The bottom panel shows the same graphs after removing individual means. In contrast to the analogous search time graphs, both of the reservation wage ratio graphs display no tendency for the reservation wage to decline over the spell of unemployment.

This conclusion is also borne out in the regressions in Table 4.2, which regress the reservation wage ratio on unemployment duration and other variables. While the models in the first two column show a gradual decline in the reservation wage relative to the preunemployment wage over the spell of unemployment, the fixed effects estimates in columns 3 and 4 find a statistically insignificant and trivially small change in the reservation wage as unemployment duration increases. Moreover, the reservation wage appears insensitive to periods of lapsed or exhausted benefits, and is unchanged after the November 8th extension of benefits to 99 weeks.

The right part of Table 4.2 provides additional estimates of the fixed effects specification for various subsamples. For those with more than $\$ 10,000$ in savings or older than age 50, we find a statistically significant, negative relationship between the reservation wage relative to previous pay and the duration of unemployment. ${ }^{16}$ For those who were over age 50 and had more than $\$ 10,000$ in savings at the start of the study, a spell of unemployment of 25 weeks is estimated to have reduced the reservation wage by 10 percent. The apparent willingness of older workers to lower their reservation wage the longer they are unemployed is consistent with the view that job search is an investment: the cost of accepting a lower wage job is less for those who plan to spend less time in the labor market. Older workers gradually realize that they cannot find a job

\footnotetext{
${ }^{16}$ In the entry survey, individuals with a checking, savings or money market account were asked how much savings they had.
} 
that pays as well as they expected and thus adjust their reservation wage down, whereas younger workers are willing to maintain their reservation wage for longer because it is more costly for them to accept a low paying job.

And the finding that the reservation wage is more sensitive to unemployment duration for those with some savings to start with is consistent with the idea that as workers draw down on their assets during a spell of unemployment they become less selective about which job they would accept.

After eliciting the reservation wage, the questionnaire asked, "How many minutes a day would you be willing to commute if you were offered a job at that salary?" Table 4.3 reports estimates of the same type of models as in Table 4.2, using commuting time as the dependent variable in place of the reservation wage. Unlike the reservation wage, we do find a statistically significant effect of unemployment duration on the willingness to accept a longer commute to work. The relationship is extremely modest, however. A 25 week increase in unemployment is only associated with a 2.3 minute increase ( 5 percent of the average) in the amount of time individuals said they were willing to travel to work in our fixed effects models. Thus, as practical matter, based on their responses job seekers do not seem particularly willing to accept a job that requires a longer commute or that pays a lower wage as their duration of unemployment increases.

\section{Analysis of UI Exits and Job Offer Generation Process}

In the 39,201 weekly observations in our survey, there are 2,626 reports of wage offers having been received. ${ }^{17}$ The same worker could receive a wage offer in different weeks, or multiple offers in the same week. In total, 1,224 of the 6,025 respondents reported receiving at

\footnotetext{
${ }^{17} \mathrm{We}$ do not impose an age restriction on the sample used in this section in order to increase the sample size.
} 
least one job offer in the period of study. ${ }^{18}$ Nearly a third of the wage offers were for part-time jobs (32 hours or less per week).

Table 5.1 provides a tabulation of the likelihood of receiving a full- or part-time job offer by whether a full- or part-time job was sought. Because individuals may have received an offer after they stopped responding to the survey, we also report the percent of individuals who left UI before exhausting benefits even though we have no report of them having received a job offer. Among those who indicated in the entry survey that they were looking for a part-time job, 15.9 percent received at least one part-time offer, more than double the rate for those who indicated they were looking for a full-time job (6.5\%). And among those who were looking for a full-time jobs, full-time job offers were about 50 percent more likely to have been received (15.6\% vs. $10.1 \%$ ). The average hourly wage offered was $\$ 19.50$ for full-time jobs, $\$ 16.50$ for part-time jobs and $\$ 18.65$ overall. ${ }^{19}$

In 23 percent of job offers, workers said they knew exactly what the job would pay when they first interviewed for it. ${ }^{20}$ Three quarters of job offers were of the take-it-or-leave-it variety, while the remainder entailed some bargaining over pay. For a sample hired during a more normal job market, Hall and Krueger (2010) found that $82 \%$ of workers who did not have the option of keeping their previous job accepted a job with a take-it-or-leave-it offer, so the recession does not appear to have reduced the prevalence of bargaining.

\footnotetext{
${ }^{18}$ In the survey, respondents could indicate job offers received in the last 7 days as well as job offers they received since the last interview if they skipped one or more interviews. However, details about the job offer (wage, hours, etc.) were only asked if it was received in the last 7 days, or if the job offer was accepted. Moreover, if respondents indicated that they received more than one job offer in a given week, details about the job offer were only asked about the "best" offer. Overall, we know the details of 2,036 job offers out of a total of 2,626. In much of the analysis below, we only use information on job offers received in the last 7 days to avoid selection bias.

${ }^{19}$ For these statistics, we use only job offers in the last 7 days because for other job offers that were made since the last interview we only know hours and wages if these offers were accepted.

${ }^{20}$ Another 36 percent said they had some idea about the pay and 30 percent said they had very little idea; 12 percent of workers received a job offer without interviewing for it. The offered wage was above the reservation wage in 59 percent of full-time offers when workers knew the pay exactly at the time of the interview, and only 32 percent of cases when they had very little idea. These results suggest that a subset of workers engage in directed search.
} 
A significant share of the sample $-6.6 \%$ overall, which is about one third as large as the share that reported job offers - left UI before exhausting benefits but did not report a job offer. We suspect that many of those who left UI early received job offers but did not report them in our survey because they stopped participating in the survey. For this reason, we model the likelihood of leaving UI early as a function of past search activity as well as model the likelihood of receiving a job offer.

For members of each cohort, Figure 5.1 displays the probability of having received at least one job offer by the specified date, treating those who stopped responding to the survey as censored. The ogives are surprisingly similar across cohorts, although those who have been unemployed for a shorter period of time have greater odds of receiving a job offer over the ensuing weeks. Notice also that the ogives exhibit only a slight inclination to flatten at longer durations despite the downward trend in search time over the spell of unemployment found in Figure 3.1a and 3.1b. (This pattern is consistent with the weak relationship between search time and the likelihood of receiving a job offer found in Table 5.2 below.)

As mentioned, a limitation of our data is that we lack information on job offers received by workers who stopped responding to our survey. Nonetheless, workers who receive a job offer are more likely to exit UI early (i.e., before their benefits are exhausted). Specifically, 34.7 percent of those who reported receiving a job offer at some point during our survey window exited UI early, compared with 8.2 percent of those who did not report receiving a job offer. ${ }^{21}$ For full-time job offers the differential was even greater: 41.4 percent of those who received a full-time offer exited early vs. 8.7 percent of those who did not. Some of those who received a full-time job offer did not exit UI early because they rejected the offer, or because they accepted

\footnotetext{
${ }^{21}$ These figures exclude those who exited UI at 51 or 52 weeks because, as explained previously, many of these exits did not involve finding a job.
} 
the offer but subsequently became unemployed again and remained on the same benefit spell or because their job started after they exhausted benefits.

In view of the missing data problems and ambiguity about the time lag between search activity and job offers, we take a simple approach to modeling job offers and UI exits. Specifically, we view the available data on job search and the reservation wage as having been sampled from the unemployment spell. Some workers search more than others, and we use the available data on search time during unemployment to represent the worker's search intensity. Because search intensity falls with the duration of unemployment, we first regress search time on individual dummy variables and dummies indicating the duration of unemployment for each cohort using up to 12 weekly observations for each individual. ${ }^{22}$ The coefficients on the individual dummy variables (or fixed effects) from these regressions provide a measure of the workers' search intensity. We performed an analogous exercise for the reservation wage relative to the previous wage.

We then estimated a probit model where the dependent variable is 1 if the individual left UI in the 24 weeks since we began interviewing without exhausting benefits and 0 otherwise, and the explanatory variables are the estimated search time and reservation wage individual fixed effects and other variables, such as whether recall was expected. We estimate a parallel model where the dependent variable is 1 if a job offer was received at some point in our sample period, and 0 otherwise. (The reservation wage was not used as an explanatory variable in the job offer equation because it should affect the likelihood of accepting a job offer, not of receiving one.)

Table 5.2 summarizes various estimates for models predicting an early exit from UI and receipt of at least one job offer. First consider the results for exiting UI early in columns 1-3. The results accord with standard search theory: workers who devoted more time to searching for

\footnotetext{
${ }^{22}$ We restrict the sample to those with two or more weekly observations.
} 
a job were more likely to exit UI early, as were those with a lower reservation wage relative to their past wage. Those who searched 20 hours more per week are about 3.5 percentage points, or 20 percent, more likely to exit UI early. Having a 20 percent lower reservation wage is associated with a 1 percentage point, or 6 percent, increase in the likelihood of exiting UI early. The magnitudes of the estimates are relatively small, but they are probably downwardly biased because of sampling error owing to the small number of weeks observed. ${ }^{23}$

If we divide the sample by education, we find that the reservation wage is a stronger predictor for those with less than a college degree, while search time is a stronger predictor for college graduates. Turning to the other variables in column 3, workers with a definite recall date at the start of the survey are more likely to exit UI, as are workers with a college degree or higher and married workers.

The model does a less good job predicting the receipt of a job offer than it does predicting exit from UI. Surprisingly, receipt of a job offer is unrelated to job search time in our sample, and demographic characteristics are mostly insignificant predictors as well. When we disaggregate job search time into different activities, the only one that predicts the receipt of a job offer is time spent on job interviews.

\section{To Accept or Not Accept (a Job Offer)}

About 60 percent of job offers are accepted. There are many reasons why a job offer may be turned down. For example, workers may expect to receive a better offer soon, or the offered wage may be below the worker's reservation wage level.

\footnotetext{
${ }^{23}$ Attenuation bias due to sampling variability is likely small for the reservation wage, however, because it is very stable over time. See Jones (1988) for cross-sectional evidence on how the reservation wage relates to unemployment duration for a sample of 854 unemployed British workers.
} 
Past studies have not been able to assess the validity of self-reported reservation wage data because they have relied on cross-sectional data. Table 6.1 presents evidence on the likelihood that a worker accepts or rejects a job offer depending on whether the offered wage was above or below the reservation wage. To avoid possible bias due to cognitive dissonance, the reservation wage is taken from the most recent prior survey, and therefore not contemporaneous with the report on whether the job offer was accepted or rejected. The reservation wage and offered wage, which could be reported for different time units (i.e., hourly wage versus weekly salary), were both transformed to hourly earnings, which introduces some noise because the hours data entail some error.

For the full sample, workers are 24 percentage points more likely to accept an offer that equals or exceeds the reservation wage than one that is below it, and 13 percentage points more likely to reject an offer that is below the reservation wage than one that equals or exceeds it. If we restrict the sample to offers of full-time jobs, the predictive power is a bit stronger: workers are 30 percentage points more likely to accept offers that equals or exceed the reservation wage than one that is below it. The fact that 44 percent of respondents accepted a job that paid less than the stated reservation wage suggests that the reservation wage is not a perfect measure, but it should be borne in mind that there is some noise in both the reservation wage and the offered wage because of errors in the hours data.

Table 6.2 presents probit regressions where the dependent variable is 1 if an offer has been accepted and 0 if it has been rejected or a decision has not yet been made. The first column indicates that workers are more likely to accept a job that pays more than their reservation wage, although the interaction between part-time job status and being above or below the reservation wage indicates that the reservation wage cutoff does not predict acceptance of part-time jobs. As 
we saw in Table 6.1, workers are willing to accept part-time jobs even if they pay less than their reservation wage. The value of the reservation wage itself does not predict whether a job is accepted once a binary indicator of whether the reservation wage exceeds the offered wage is held constant. The value of the offered wage, however, has predictive power conditional on whether the wage exceeds the reservation wage. One interpretation of the latter finding is that jobs that offer a higher wage compensate for undesirable conditions that are not adequately reflected in the reservation wage (e.g., commuting distance), and thus whether the reservation wage exceeds the offered wage is not a sufficient statistic for job acceptance or rejection. Nonetheless, a binary indicator of whether the reservation wage exceeds the offered wage is a strong predictor of job acceptance or rejection.

The importance of the reservation wage exceeding the offered wage can be seen in Figure 6.1 as well. Specifically, we varied the proportion, $\mathrm{X}$, by which the reservation wage was required to exceed the offered wage for the binary variable to be set to one. If the reservation wage is $\mathrm{R}$ and the offered wage is $\mathrm{W}$, a binary variable was created that equaled one if $\mathrm{W} \geq$ $(1+\mathrm{X}) \mathrm{R}$, and zero otherwise. We varied $\mathrm{X}$ from -30 percent to +30 percent, and re-estimated the model in column 1 of Table 6.2. Figure 6.1 shows the effect of this variable on job acceptance at varying levels of $\mathrm{X}$. A discrete jump in predictive power occurs at the point at which the reservation wage just exceeds the offered wage for full-time job offers, suggesting there is a discontinuous effect as the offered wage approaches the reservation wage.

Recall that, on average, the reservation wage is close to the previous wage. If we use the previous wage in place of the reservation wage, however, the probit equation does not predict job acceptance as well as if we use the reported reservation wage (compare column 1 and 2 of Table 6.2). Moreover, if we include a pair of indicators for whether the reservation wage and previous 
wage exceed the offered wage in the same equation, the reservation wage indicator has the expected sign and is statistically significant at the $1 \%$ level, while the coefficient on the previous wage indicator is about half as large and insignificant with a t-ratio of 1.5 (see column 3 ). These results suggest that the reservation wage captures more information than the previous wage.

Column 4 indicates that savings and unemployment duration do not predict job acceptance conditional on the reservation wage. Because the reservation wage should be a sufficient statistic for workers' requirements, factors that affect their financial predicament or duration of job search should be irrelevant conditional on the reservation wage. The probit estimates are consistent with this prediction.

Despite the predictive power of the reservation wage, close to half of those who were offered a job paying less than their reservation wage accepted it. These cases could represent measurement errors (e.g., because of errors in work hours), or weaknesses in the reservation wage data -- or in the reservation wage concept itself. In Table 6.3 we estimate probit equations to examine factors that predict the likelihood of accepting a job that pays less than the reservation wage for the subset of searchers who were offered such jobs. The very long term unemployed (79 weeks or longer) were more likely to accept jobs that paid below their stated reservation wage, although duration of unemployment did not matter for those who were unemployed for less than 79 weeks. In addition, those who rated themselves as very willing to take risks were less likely to accept jobs that paid below the reservation wage, but those who took the immediate $\$ 20$ incentive payment over the delayed $\$ 40$ payment were not more likely to accept such job offers. ${ }^{24}$ Lastly, less educated workers and blacks were less likely to accept jobs

\footnotetext{
${ }^{24}$ The specific question was: "Please rate yourself on a scale between 0 and 10 , where 0 means 'unwilling to take risks' and 10 means 'very willing to take risks'." Individuals were coded as risk takers if they rated themselves above 5 .
} 
offering less than the reservation wage. These results suggest that the mispredictions of the reported reservation wage are not random, although there is little evidence of systematic bias by unemployment duration for workers who are unemployed less than 79 weeks.

\section{Conclusion}

Several findings in this paper shed light on job search behavior in a depressed job market. Some findings are consistent with the Mortensen (1977) sequential job search model and others are inconsistent with it. In contrast to the prediction of sequential, stationary job search model, we find that the amount of time devoted to job search declines sharply over the spell of unemployment. Because temporal factors (e.g., seasonality or benefit extensions) could have distorted job search in our sample, it would seem to us to be a priority to determine if this pattern can be replicated in future research using longitudinal data for other time periods. Assuming that the declining search profile is robust, there are three likely explanations for this phenomenon. First, workers could exhaust suitable jobs to apply to the longer they are unemployed, and wait for more jobs to become available, rather than spend time searching as their spell of unemployment progresses. Second, search efficiency could rise with time spent searching. Third, workers could become discouraged the longer they are unemployed, and this could prevent them from applying for available jobs. Distinguishing among these explanations is very important, as the latter behavior could lead to hysteresis and prolonged joblessness after the job market improves.

The reservation wage appears to behave in a fashion that is consistent with standard search theory in that it is very stable for most workers. However, one may question whether, compared to the optimal, unemployed workers' reservation wages are too rigid and too high: the average reservation wage is close to the previous wage and does not seem to respond to the 
exhaustion of benefits. For older workers, however, we do find a decline in the reservation wage over the spell of unemployment. In addition, while we do not find that workers increase their search time as their benefits run out, we do find that they lower their sights as they exhaust their own personal savings. In particular, those who had more than $\$ 10,000$ in liquid assets at the start of the study were more likely to lower their reservation wage over the course of their spell of unemployment, compared with those with a smaller amount of savings to start with. This finding suggests that people treat government provided social insurance differently from their own personal precautionary savings.

Our finding that the (lagged) reservation wage predicts job acceptance or rejection is an encouraging result for researchers, as is the finding that the reservation wage conveys information beyond that in the previous wage. Including a question on unemployed workers' reservation wages in ongoing labor force surveys would seem to us to be a useful addition. ${ }^{25}$

For offers of part-time jobs, however, workers tend to be less choosey. The reservation wage does not predict acceptance or rejection of part-time jobs. One explanation for this finding that we plan to explore in future work is that a part-time job could be a bridge to a full-time job. In addition, workers can continue searching for a full-time job even if they work part time. The fact that part-time workers can receive partial UI benefits in New Jersey may make it easier for the unemployed to accept a part-time job that pays less than the reservation wage. Increasing the availability of part-time jobs could help job seekers transition back to work. In future work, we plan to examine whether full-time job seekers who accept part-time jobs are more likely to subsequently find a full-time job than otherwise similar individuals who reject part-time job

\footnotetext{
${ }^{25}$ Shimer and Werning (2007) provide a model suggesting that the reservation wage provides a sufficient statistic for worker welfare, and also encourage future research to study how labor market policies affect reservation wages.
} 
offers, as well as compare subsequent job search time after workers accept or reject a part-time job offer.

We find mixed results concerning extended unemployment benefits. On the one hand, workers do not search more or lower their reservation wage in periods when their UI benefits have lapsed or been exhausted, suggesting that EUC did not provide a serious disincentive to finding a job. On the other hand, we find that average search time was lower for workers as a whole after the maximum duration of benefits was extended from 79 to 99 weeks, although this finding is sensitive to the functional form of the unemployment duration variable, the particular measure of job search, and possibly confounded by other temporal factors, such as seasonality. In future work, we plan to examine the effect of EUC on consumption.

Lastly, the findings that the reservation wage and job search time predict early exits from UI highlight the importance of understanding these variables for public policy. Interventions that encourage more search effort and more moderate reservation wages could help to speed the return to work, although the magnitude of the effect of the reservation wage on exiting UI is relatively small because receipt of job offers is relatively rare in our sample. In future work, we plan to more fully explore the timing of the relationship between job search activities, the receipt of job offers, and exits from UI. 


\section{Appendix: Description of Survey and Data Coding}

On October 1, 2009, the Princeton University Survey Research Center (PSRC) obtained a complete list of the roughly 360,000 individuals receiving UI benefits in New Jersey as of September 28, 2009. The data were subjected to a stratified random sampling procedure to obtain a sample of 63,813 UI recipients. This appendix provides a detailed description of the sampling and survey procedures.

\section{Stratified random sampling procedure}

Almost half of UI recipients in New Jersey provided their email address to the New Jersey Department of Labor and Workforce Development (LWD) when filing their claim. ${ }^{26}$ We selected workers both with and without email addresses to participate in the study. To follow relatively homogenous groups over the course of the study, we sampled eight cohorts based on how many weeks of UI benefits they had been paid on their current UI claim as of September 2009. Specifically, the cohorts were defined as those with 0-2, 10-12, 20-22, 30-32, 40-42, 5053, 60-63 and 72-77 weeks of UI benefits paid at the start of the study. Our initial design was to draw a random sample of 7,000 unemployed workers for each of the first seven cohorts $(5,000$ with email addresses on file and 2,000 without email addresses on file), and 14,000 unemployed workers for the last cohort. This sampling procedure deliberately oversampled the long term unemployed. Unfortunately, the number of unemployed workers in the seventh and eighth cohorts with email addresses was smaller than our target, so we also sampled those with 64-71 and more than 77 weeks, but in both cases we restricted the oversample to those with email address on file.

\footnotetext{
${ }^{26}$ Providing an email address is a requirement for filing an online claim.
} 
The sampling strata thus consist of 18 groups, based on the initial duration of unemployment and the availability of an email address. In total, the sample included 45,813 unemployed workers with email addresses and 18,000 without email addresses.

\section{Invitation and reminder emails}

The New Jersey Department of Labor and Workforce Development (LWD) sent out an initial email or letter a few days prior to the start of the survey to inform selected sample members about the study and to encourage them to participate. The letter also made clear that participation in the study is voluntary and that the PSRC would not share any information on specific individuals with LWD.

The initial email invitations with a link to the web questionnaire were sent out on October 13, 2009. An important component of the questionnaire was a time-use diary, which asked hourby-hour how the respondents spent the previous day. To ensure that the number of time-use diaries was more or less evenly distributed across weekdays, the sample was divided into five groups, where the first group was sent an invitation email on Tuesday morning, the second group on Wednesday morning, and so on through Saturday morning. Participants were asked to complete the survey within two days of receiving the invitation email.

Physical letters were mailed to those without email addresses during the week of October $13^{\text {th }}$. The letter provided the URL of the webpage with the questionnaire and a 9-digit survey identification number, which the individual needed to log into the survey. The letters were staggered in the same manner as the email invitations (spread out over five days). Survey participants from the letter strata were required to enter a valid email address in order for them to receive email invitations for the follow-up weekly interviews. If a respondent did not have an 
email address, he or she could nevertheless participate in the following weekly interviews by logging into the same access webpage with the same 9-digit survey identification number as in the invitation letter.

In the week from October 19-23, PSRC made nearly 10,000 phone calls to encourage those who did not respond to the initial invitation to participate in the survey. Moreover, emails were sent to nonrespondents who had an email address on file encouraging them to participate in the survey three and seven days after the initial invitation was sent out. We closed the survey for entry on November 3, when the average number of new participants had dropped to below 20 a day. ${ }^{27}$ Overall 6,025 unemployed workers participated in the survey.

Invitations to complete the follow-up weekly interviews were sent out by email seven days after the most recent online interview was completed, but not on Sundays or Mondays, because we wanted the time use diary to pertain to weekdays. ${ }^{28}$ If a participant did not complete a weekly interview within three days of receipt of an invitation, we sent a reminder email.

Further reminder emails were sent 7, 14, 21, 28 and 35 days after the last interview was completed. We encouraged people to respond to the survey even if they had already found a job.

Initially, individuals who were selected for the study were invited to participate for 12 consecutive weeks. In the beginning of January 2010, however, individuals with more than 60 weeks of UI paid at the start of the study were invited to participate in an extended study for an additional 12 weeks. Some 1,148 individuals completed at least one interview of the extended study (out of the 2,022 who were eligible). The email invitation and reminder system for the longer term survey was exactly the same as for the initial 12 weeks of the study.

\footnotetext{
${ }^{27}$ Around 5,680 unemployed workers entered the survey within the first two weeks of the survey.

${ }^{28}$ So if a respondent completed an interview on a Sunday, he or she would receive the invitation to the next interview on the Tuesday of the following week, nine days later.
} 


\section{Online survey instrument}

The online survey instrument was developed in collaboration with the Survey Research Institute (SRI) at Cornell University and consisted of two parts, the entry and the weekly questionnaire. The entry survey contained questions that were only asked once, the first time the individual completed the online survey. The questions related to the previous employment, job search, mortgage, asset holdings and the spouse's employment status. The weekly questionnaire was asked every time the participants completed the survey, and the questions related to the participant's life satisfaction, weekly food consumption, job search efforts over the previous week, reservation wage, and job offers. It also contained a time use diary about activities in the previous day. In the first online interview the weekly questions were shortened because the respondents also had to complete the entry part of the survey. Moreover, some questions in the weekly questionnaire asked at a monthly frequency to reduce respondent burden.

The time use diary covered the previous day from 7 AM to 11 PM. For each hour in the time diary, respondents could select up to two activities from a list of 21 activities. The activities were chosen to represent the most frequent time use codes in time-use surveys, such as the ATUS, and specifically included job search as an activity.

The average time to complete the weekly online survey was around 15 minutes. The entry questionnaire was much shorter and took on average only about 8 minutes to complete. ${ }^{29}$

\section{Incentives}

At the end of the first online interview, participants were given two choices: a $\$ 20$ visa gift card that would be sent to the participant within a few days or a $\$ 40$ visa gift card that would

\footnotetext{
${ }^{29} \mathrm{We}$ only have start and end time of each online interview. Some participants started the survey and then decided to return to it later in the day. We consequently excluded from the calculation of average completion time all interviews where start and end time where more than 2.5 hours apart.
} 
be sent to the participant at the end of the 12 week study period. ${ }^{30}$ The motivation for offering a choice was to elicit information on the time preference of the survey participants. The online survey instrument stressed that if the participant chose the second option, we would send the $\$ 40$ gift card regardless of whether or not they completed the follow-up weekly interviews. Almost 54 percent of respondents opted to take the immediate $\$ 20$ payment over the delayed $\$ 40$ payment. The implicit discount rate consistent with choosing the $\$ 20$ payment over the delayed $\$ 40$ payment exceeds 1,500 percent. In a probit analysis, we found that older workers, more highly educated workers, whites, and those with credit cards (perhaps indicating access to credit), were significantly more likely to select the delayed $\$ 40$ payment over the immediate $\$ 20$ payment.

In early January 2010, we invited the long-term unemployed (i.e. those with 60 weeks of UI receipt or more at the beginning of the study) to participate in the survey for an additional 12 weeks. We promised all of these subjects a $\$ 40$ visa gift card at the end of the 12 week period of the extended study.

A total of $\$ 220,000$ of incentive payments was made.

Non-response and weighting

For the first interview, the response rate of the survey was $9.7 \% .{ }^{31}$ The response rate was higher among those who were contacted by email (10.7\%) than for those who were contacted by mail (6.9\%). The number of follow-up interviews completed by each cohort was relatively similar. After the initial interview, the average respondent completed 4.1 follow-up interviews

\footnotetext{
${ }^{30}$ The decision to offer a one-time payment for participation rather than an ongoing payment for each interview completed was made to minimize record keeping and costs.

${ }^{31}$ The calculation of the response rate excluded 1,972 cases from the denominator where the address could not be certified by the Coding Accuracy Support System (CASS) of the U.S. postal service and therefore no letter was generated, or where the letter was sent but returned as non-deliverable.
} 
of a maximum of 11 (excluding the longer term follow-up), so participants in the initial survey responded to almost 40 percent of the potential follow-up interviews.

Thus, the response rate for the survey was low, as is typical of Internet surveys, but we are fortunate to have restricted access to administrative data from LWD. The administrative data encompass a large set of variables, including demographic information, the weekly UI benefit, earnings in the base year, weeks worked in the base year, number of employers in the base year, industry and occupation on the last job, the date of claim, the number of weeks of UI paid as well as the remaining balance on the UI claim. We also obtained updated UI data at the end of the study period on the weeks of UI paid, the date of the most recent UI payment on the claim and whether the person filed a new UI claim since the start of the study.

Table 2.1 in the text shows the descriptive statistics for the universe, the sample frame and the respondents. The statistics for the sample frame are relatively similar to the universe, except for the weeks of UI paid. The reason is that the stratified sample intentionally oversampled those with longer durations. There are some noticeable differences between the sample frame and the respondents, however. The respondents had higher base year earnings, higher benefit amounts, were more likely to be female, white, non-Hispanic and to have attained a college degree.

To adjust our estimates for different sampling probabilities and response rates, we created survey weights based on the administrative data. Specifically, for the initial interview we estimated a logit regression where the dependent variable was a dummy variable indicating whether the unemployed worker responded to the survey or not, and the independent variables were demographic measures, including education, age, gender, race and ethnicity (the bottom part of Table 2.1 contains the full list of demographic variables included in the models). Our 
logit model also included dummies indicating each stratum used in our sampling procedure, i.e. dummies indicating 0-9, 10-19, ., 60-69 and 70 and more weeks of UI paid interacted with a dummy for whether the person had an email address on the file or not.

Entry-wave survey weights were computed as the inverse of the predicted value of the logit regression; these weights adjust for different response rates as well as different sampling probabilities due to our stratified random sampling procedure. As one would expect Table 2.1, the weights are greater, on average, for men, Hispanics, blacks, those with a high school degree or less and those whose strata were under-sampled (i.e. those with lower durations and those without email on the file). The weights were rescaled to sum to the total number of individuals in the universe. We label these weights "person weights" as they adjust for different response rates for the first interview of the survey and do not vary with the weeks of the survey.

To derive weights for differential response rates over the 12 weeks of the survey (or 24 weeks for those who participated in the extended study), we created an analogous set of weights, labeled as "current week weights," for each week of the survey. That is, we estimated the same logit model described above each week of the survey and rescaled the weights to sum to the number of cases in the universe.

Finally, we created "strata weights" for the sample frame which simply reflect the different sampling probabilities due to our stratified random sampling procedure, but do not adjust for differential response across demographic groups. These weights are used to compare the stratified sample frame with the universe or with the weighted sample of respondents (weighted with the person weights or the current week weights).

Columns 4 and 5 of Table 2.1 report weighted descriptive statistics for the sample frame and the respondents. Comparing the universe and the weighted sample frame to the weighted 
statistics of the respondents in Column 5, one finds that the demographics are very similar for these three samples. In particular, the share of college graduates changed from $40.7 \%$ for the non-weighted respondents in Column 3 to $18.7 \%$ for the weighted respondents in Column 5, which is very close to the universe and the weighted sample frame (19.0\%). This is not surprising as education dummies and other demographic data were used to create the survey weights. As an out of sample test, one can compare the weighted statistics of variables that were not used in the creation of the survey weights. Most importantly, the weighted earnings during the base year $(\$ 37,960)$ are reasonably close to earnings in the base year in the universe $(\$ 35,335)$. The industry composition of the weighted respondents is also relatively similar to the universe, although construction workers are underrepresented among the respondents. Finally, weeks of UI paid are slightly lower for the weighted respondents than for the universe. This is because the universe includes workers of all durations whereas the stratified sample frame includes only workers from 0-2 weeks, 10-12 weeks, etc. When comparing the stratified sample frame to the respondents, weighted and unweighted, the weeks of UI paid are very similar, suggesting that response rates were similar across unemployed workers with different durations.

\section{Data coding and trimming}

\section{Base year earnings above the top code}

Earnings were topcoded at $\$ 99,999$ in the administrative data. Some 3.8 percent of observations had earnings above the top code. We follow the procedure outlined by Feenberg and Poterba (1993) to impute earnings above the top code. Specifically, Feenberg and Poterba assume that earnings above a certain percentile follow the Pareto distribution and estimate the two parameters of the Pareto distribution with earnings for the part of the distribution that is not 
top-coded. More precisely, the CDF of the Pareto distribution is $F(e)=1-(\mathrm{k} / \mathrm{e})^{\alpha}$ and we estimate the parameters $k$ and $\alpha$ with base earnings at the $90^{\text {th }}$ percentile (where $F\left(e_{p 90}\right)=0.9$ and $\left.e_{p 90}=68,866\right)$ and base earnings at the top code (where $F\left(e_{t c}\right)=0.9663$ and $\left.e_{t c}=99,999.99\right)$. The estimated parameter values are $\mathrm{k}=31,266$ and $\alpha=2.916$, and the implied mean above the top code is:

$E\left(e \mid e>e_{t c}\right)=\frac{1}{1-F\left(e_{t c}\right)} \int_{e_{t c}} e f(e ; k, \alpha) d e=152,190.5$

where $f(e ; k, \alpha)=\alpha k^{\alpha} e^{-(\alpha+1)}$ is the density of the Pareto distribution.

To eliminate some apparent mistakes, in our analysis sample we trimmed a small number of observations (1.3 percent) whose ratio of weekly benefits to weekly earnings exceeded 2.0.

Hours on previous job for those who indicated "hours varied" or have missing hours

Around $18 \%$ of the respondents reported "hours varied" on their previous main job (question e1) or on their previous other jobs (question e3). We imputed hours for this group and for those few cases with missing hours data using the following procedure: First, we estimated separate regressions for men and women where the dependent variable was hours and explanatory variables were age, race, ethnicity, education, marital status, presence of children and on a dummy for whether the person had more than one job. Then we computed the fitted value of this regression to impute hours for those who indicate "hours varied" or have missing hours. If hours varied only for the other jobs (e3), then we added the coefficient estimate for the dummy "had more than one job" to the hours reported for the main job (e1).

Weekly and hourly previous wage 
We computed the weekly previous wage by dividing the base earnings by the number of weeks worked in the base year (the "base weeks"), and the hourly previous wage by dividing the weekly previous wage by the hours reported in the survey. We trimmed observations with previous weekly earnings greater than $\$ 8,000$ or less than $\$ 100$ and with previous hourly wages greater than $\$ 100$ or less than $\$ 5$.

\section{Reservation wages and Offered Wage}

Our reservation wage question was almost identical to the 1976 CPS question analyzed by Feldstein and Poterba. We trimmed 2,234 out of 36,514 observations with reservation wage ratios greater than 3 or less than $1 / 3$, following the same procedure as Feldstein and Poterba (1984). We defined the reservation wage ratio as the weekly reservation wage divided by the weekly previous wage, because with weekly wage data we avoid using imputed hours for those who indicated that hours varied on their last job. We also trimmed observations with weekly reservation wages greater than $\$ 8000$ or less than $\$ 100$, and with hourly reservation wages greater than $\$ 100$ or less than $\$ 5$. This caused us to exclude an additional 458 observations.

In our analysis of job offers, we trimmed observations with weekly offered wages more than $\$ 8000$ or less than $\$ 100$ and with hourly offered wages more than $\$ 100$ or less than $\$ 5$.

\section{Time spent on job search}

In our analysis of the time spent on job search (yesterday), we only use observations where at least 14 out of 16 episodes in the time diary are filled in, and where the respondents indicated at least 4 different activities over the course of the day. Around $7.8 \%$ of the diaries did not meet these quality criteria and were excluded from our analysis. Respondents could check 
two activities in each one hour interval. If two activities were reported, we assigned 30 minutes to each activity.

We computed the total amount of time spent on job search in the past week as the sum of time spent on the different job search methods. If a respondent indicated that she or he did not search over the last 7 days (question q9a), then the total amount of time is set to zero. We trimmed observations if the total amount of time spent on job search exceeded 80 hours a week. We also trimmed observations if time spent on a job search method was missing. Overall, 1.3\% of the interviews were excluded from our analysis of time spent on job search in the last 7 days because of trimming. 


\section{References}

Bound, J., Krueger, A.B., 1991. "The Extent of Measurement Error in Longitudinal Earnings Data: Do Two Wrongs Make a Right?" Journal of Labor Economics 9(1), 1-24.

Feenberg, D., Poterba, J., 1993. "Income Inequality and the Incomes of Very High Income Taxpayers: Evidence from Tax Returns," NBER Working Papers 4229, National Bureau of Economic Research.

Feldstein, M., Poterba, J., 1984. "Unemployment insurance and reservation wages," Journal of Public Economics 23(1-2), 141-167.

Granovetter, Mark. Getting a Job: A Study of Contacts and Careers. Cambridge, Mass.: Harvard University Press, 1974.

Hall, R.E., Krueger, A.B., 2010. "Evidence on the Determinants of the Choice between Wage Posting and Wage Bargaining," NBER Working Papers 16033, National Bureau of Economic Research.

Holzer, H.J, 1988. "Search Method Use by Unemployed Youth," Journal of Labor Economics 6(1), 1-20.

Jones, S.R.G., 1988. “The Relationship Between Unemployment Spells and Reservation Wages as a Test of Search Theory," Quarterly Journal of Economics 103(4), 741-65.

Katz, L.F., Meyer, B.D., 1990. "Unemployment Insurance, Recall Expectations, and Unemployment Outcomes," Quarterly Journal of Economics 105(4), 973-1002.

Krueger, A.B., Mueller, A., 2010. "Job search and unemployment insurance: New evidence from time use data," Journal of Public Economics 94(3-4), 298-307.

Meyer, B.D, 1990. "Unemployment Insurance and Unemployment Spells," Econometrica 58(4), 757-82.

Moffitt, R., 1985. "Unemployment insurance and the distribution of unemployment spells," Journal of Econometrics 28(1), 85-101.

Mortensen, D.T., 1977. "Unemployment insurance and job search decisions," Industrial and Labor Relations Review 30(4), 505-517.

Shimer, R., Werning, I., 2007. "Reservation Wages and Unemployment Insurance," Quarterly Journal of Economics 122(3), 1145-1185. 
Figure 2.1: UI weekly exit rate by UI duration
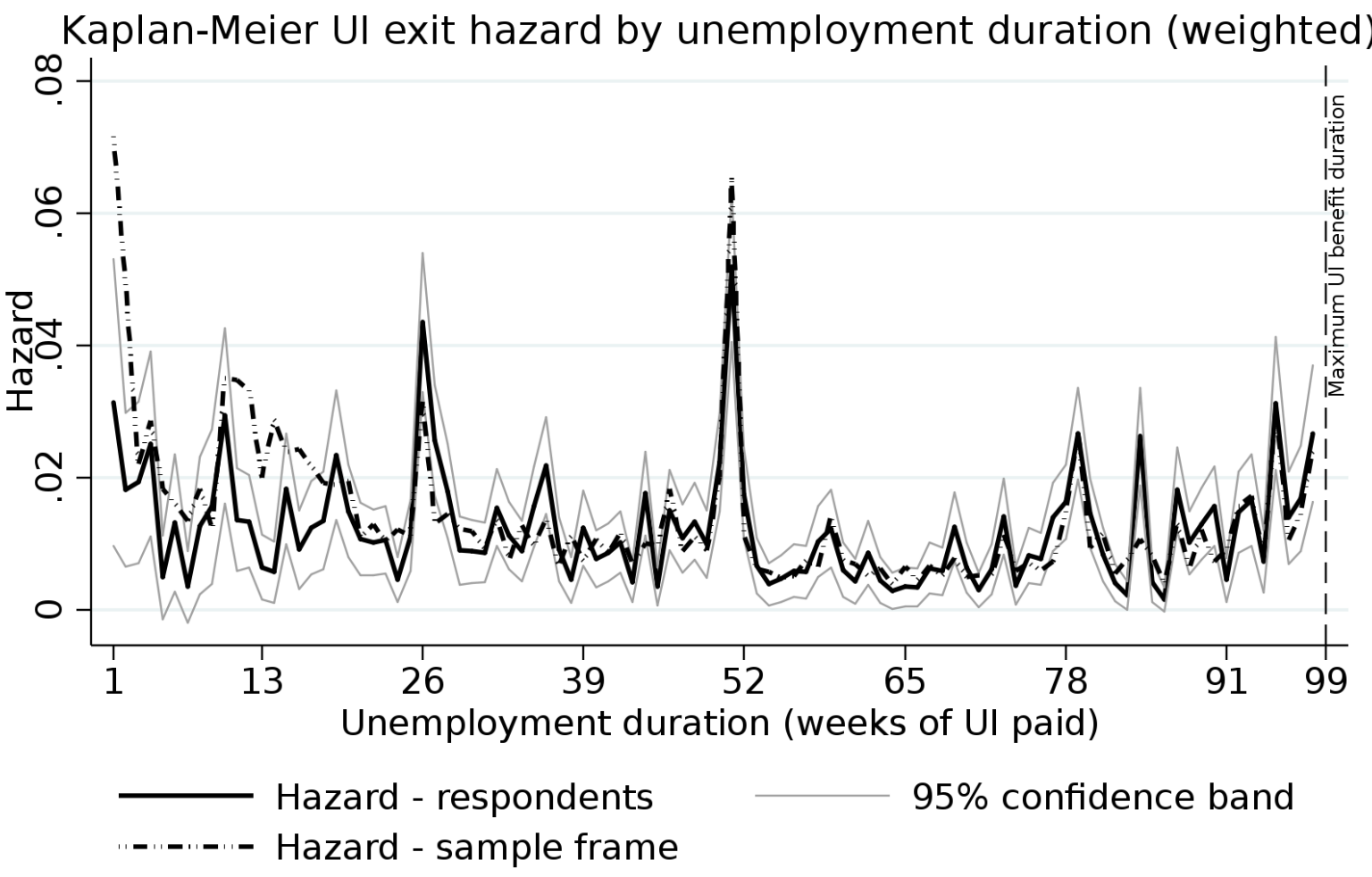

$95 \%$ confidence band

Notes: For respondents the hazards are weighted with survey weights and for the sample frame with strata weights. The confidence bands for the sample frame are not shown because the standard errors are usually small (around 0.001 , but higher for less than 20 weeks of unemployment duration). 


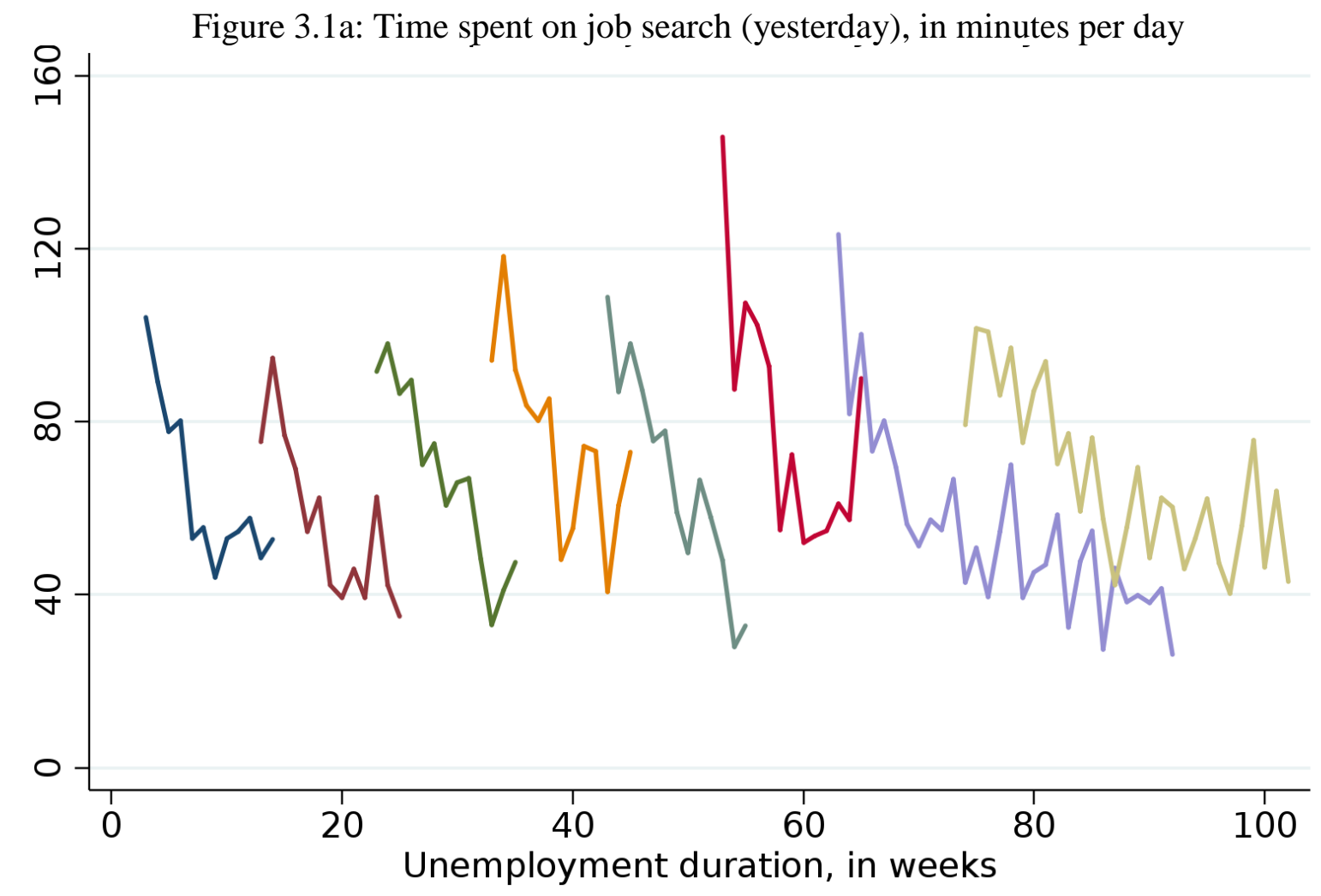

Figure 3.1b: Time spent on job search (last 7 days), in minutes per day

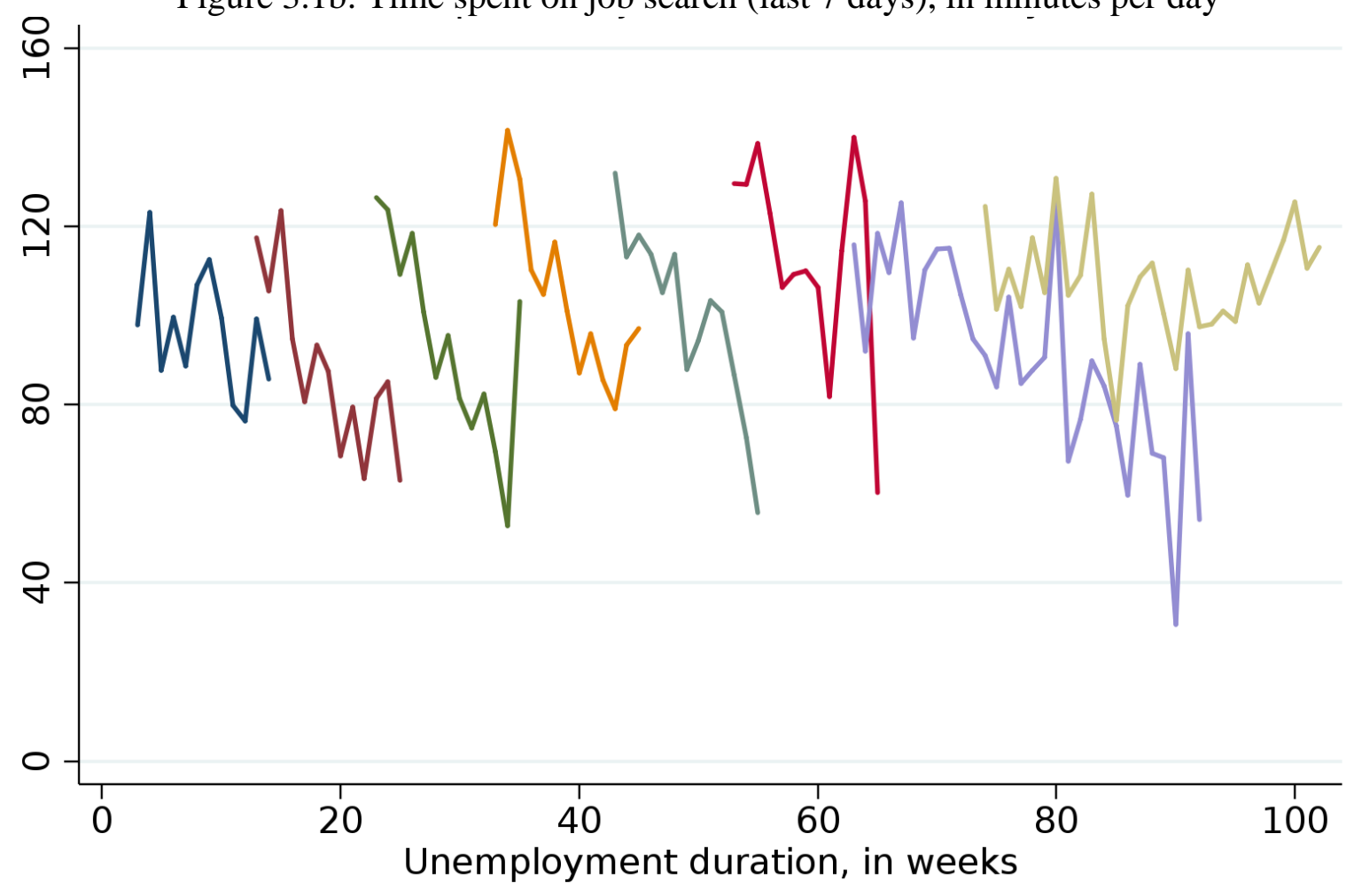


Figure 3.2: Time spent on job search methods (percent of total)

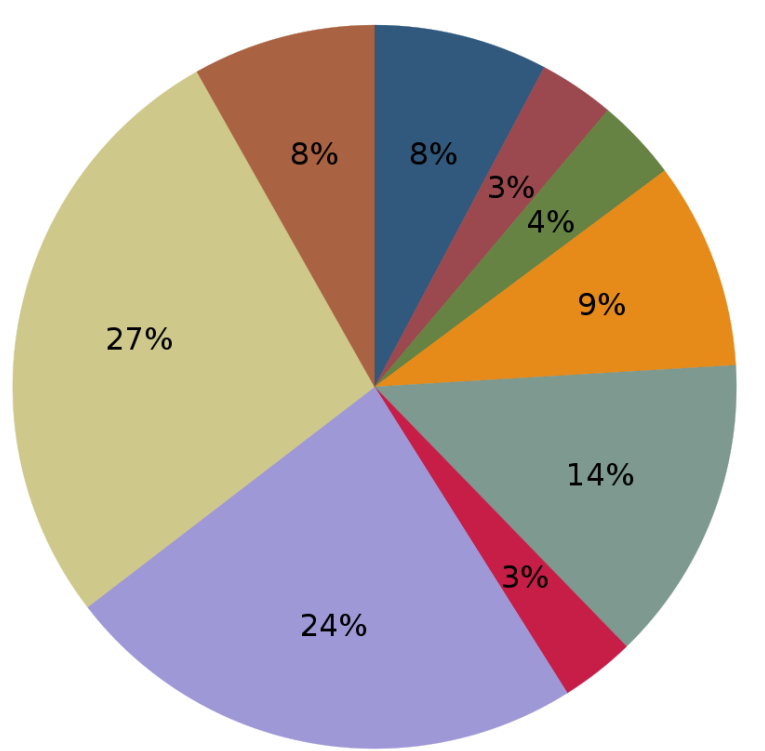

\begin{tabular}{|l|l|}
\hline Contacted employer directly & Public employment agency \\
\hline Private employment agency & Friends or relatives \\
Placed or answered ads & Went to interview \\
Sent out resumes/applications & Looked at ads \\
Other & \\
\hline
\end{tabular}


Figure 3.3: Average Earnings in Base Year, by Cohort and Duration of Unemployment

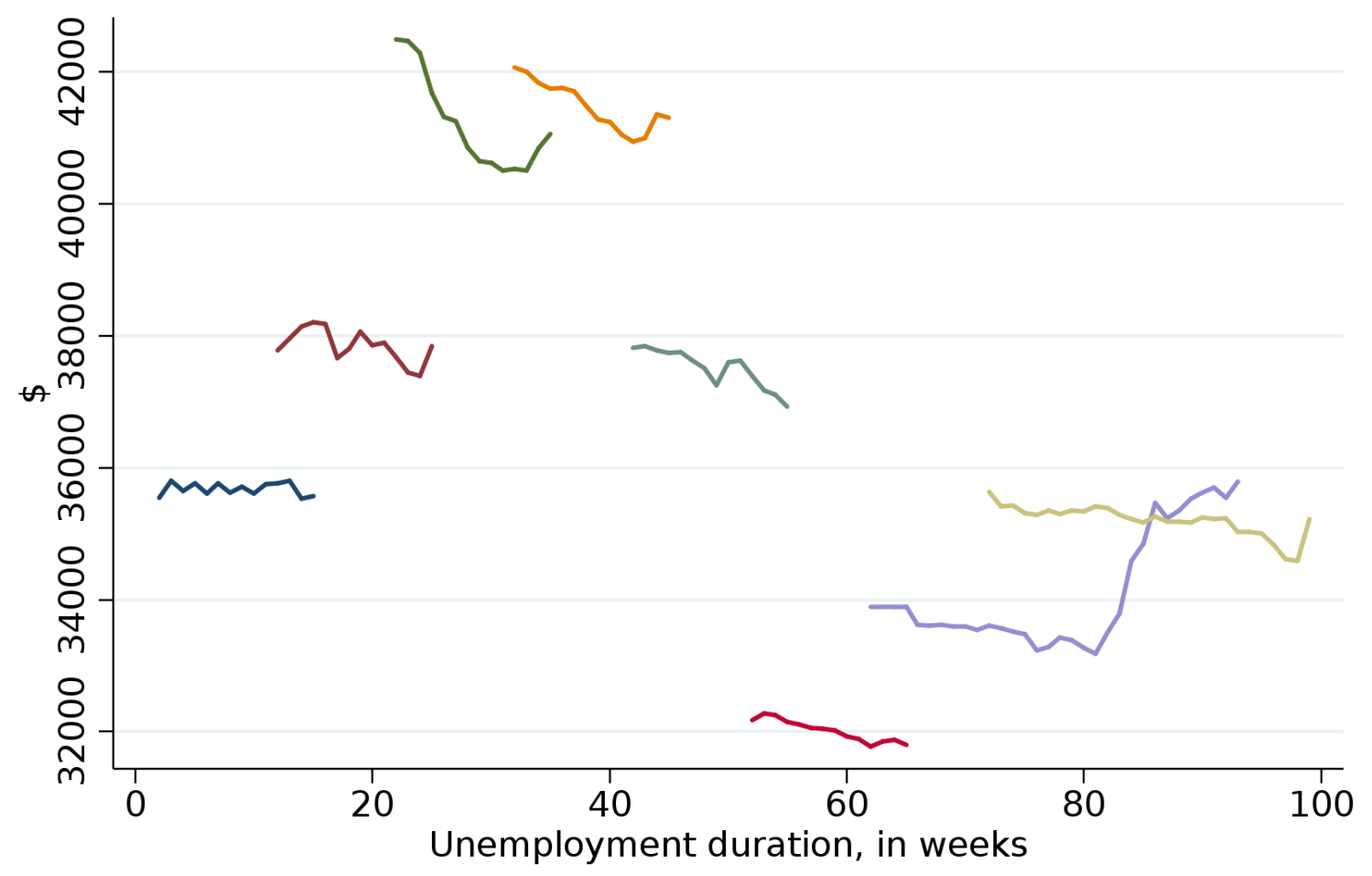

Notes: Survey weights are used. Universe: UI recipients; age 20-65. 
Figure 4.1: Average Ratio of Reservation Wage to Previous Wage, by Duration
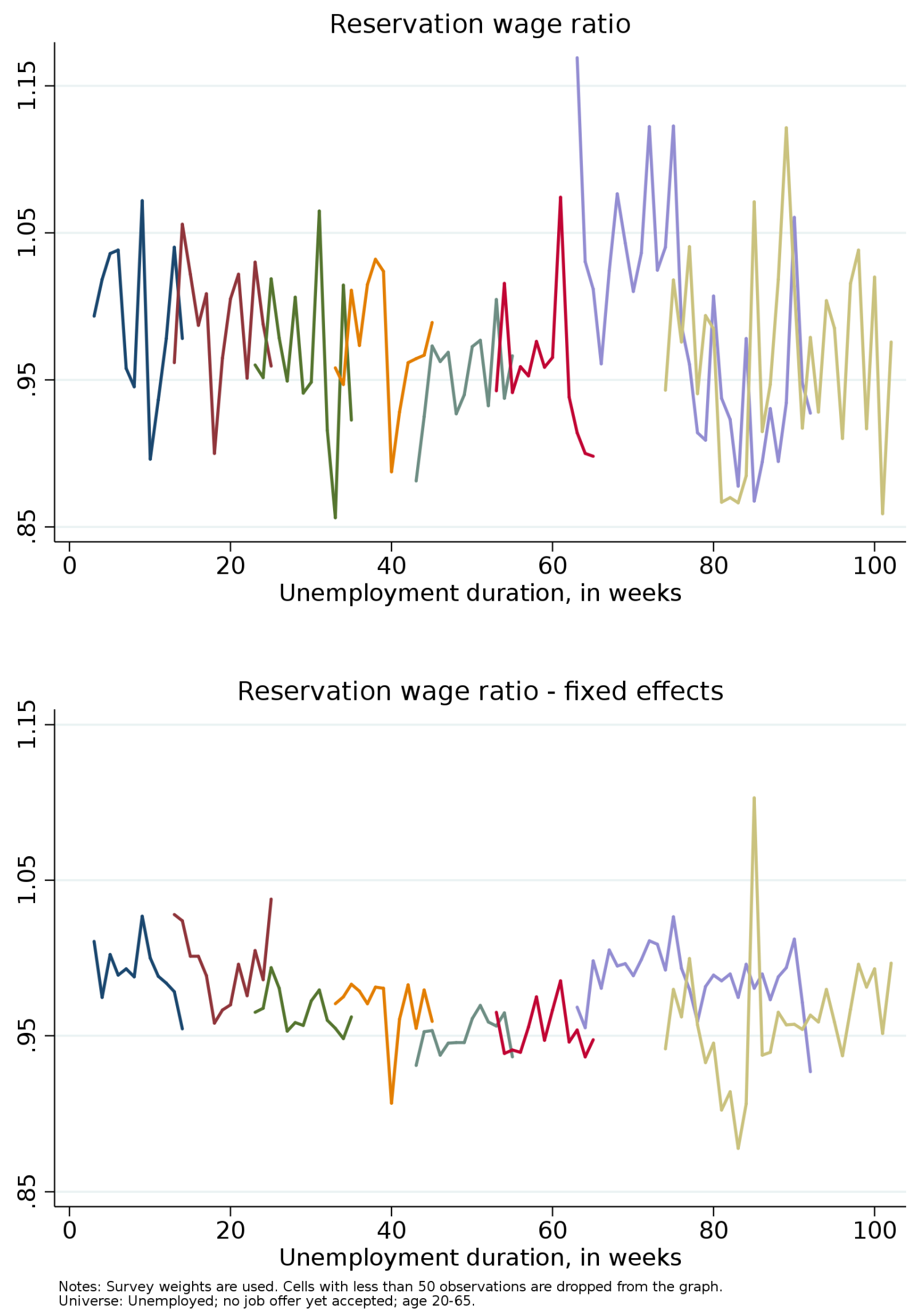
Figure 5.1: Cumulative Probability of Receiving at Least One Job Offer

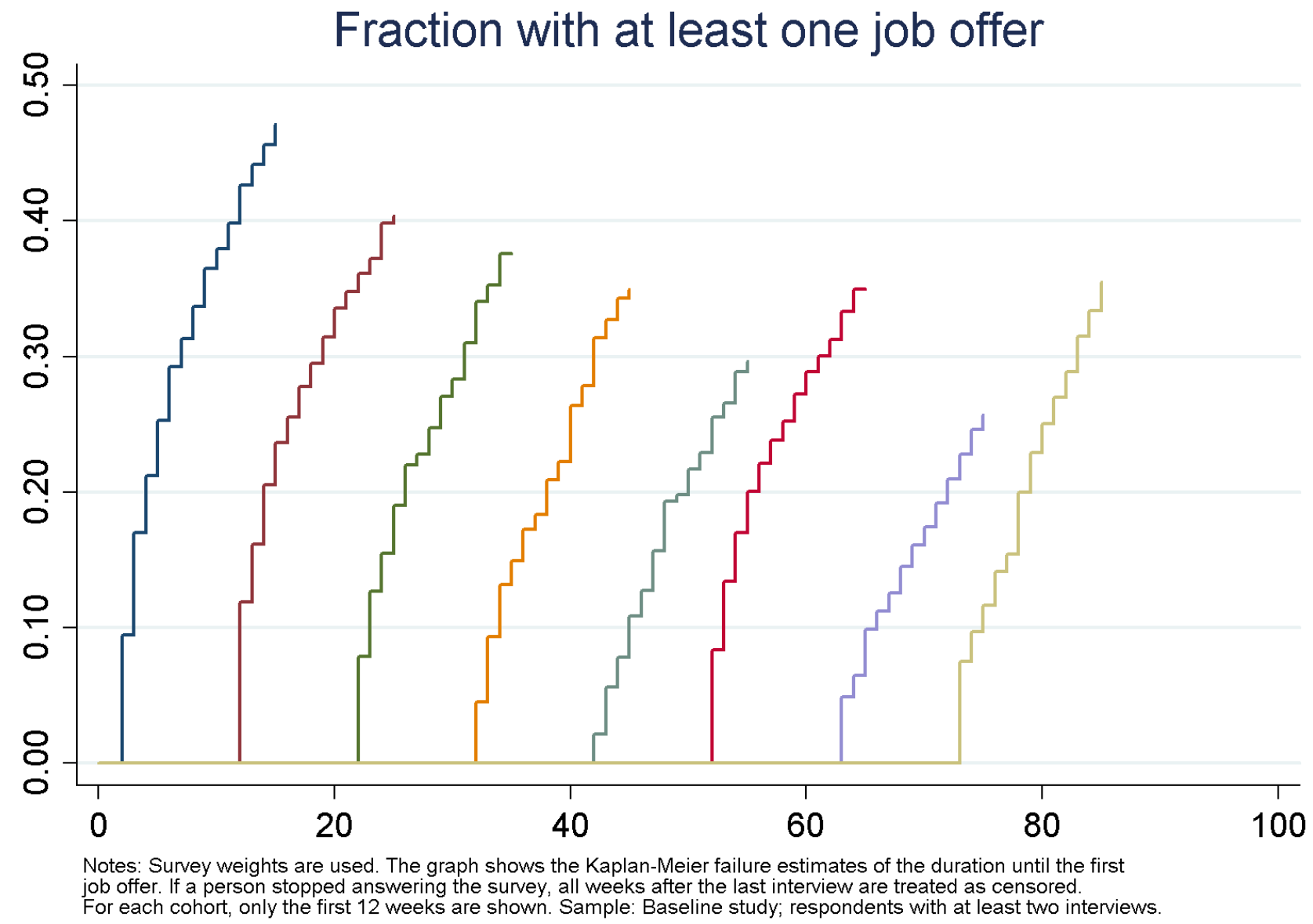


Figure 6.1: Effect of Alternative Cutoffs for Reservation Wage Relative to Offered Wage on Chance of Accepting Job

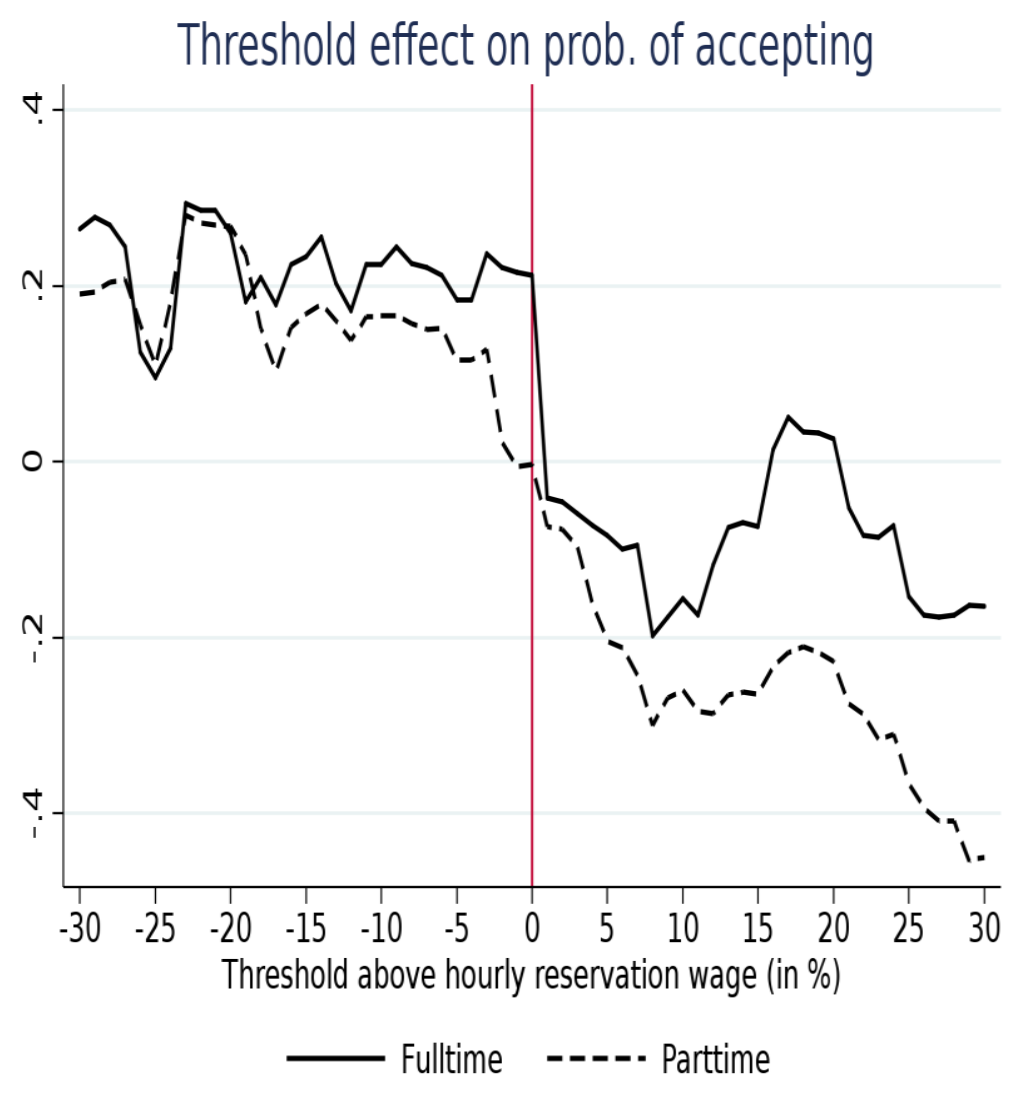

Notes: Figure shows the effect of varying the reservation wage threshold on job acceptance. Specifically, if the reservation wage is $\mathrm{R}$ and the offered wage is $\mathrm{W}$, a binary variable was created that equaled one if $\mathrm{W} \geq(1+\mathrm{X}) \mathrm{R}$, and zero otherwise. The horizontal axis shows the effect of alternative values of $X$ on job offer acceptance. 
Table 2.1 Descriptive statistics for universe, stratified sample frame and respondents

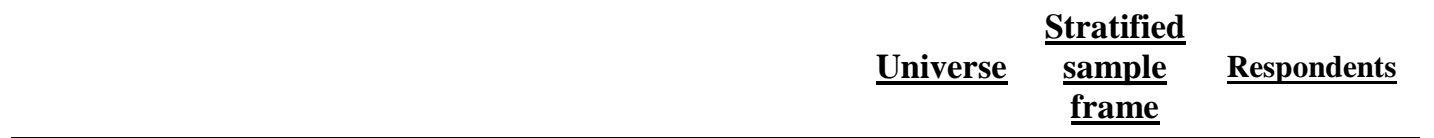

Number of observations

362,292

63,813

6,025

\begin{tabular}{lc}
$\frac{\text { Weighted }}{\text { stratified }}$ & $\begin{array}{c}\text { Weighted } \\
\text { respondents }\end{array}$ \\
\hline 63,813 & 6,025
\end{tabular}

UI and wage data

Base weeks worked during base year, in weeks

Weekly benefit rate, in $\$$

Number of employers in base year

Industry: \% construction

Industry: $\%$ manufacturing

Industry: \% educational and health care services

Industry: \% retail trade

Industry: \% professional, scientific and technical services

Industry: \% finance and insurance

Industry: \% adm., support and remediation services

Potential duration of regular UI benefis, in weeks

New claim since start of study

Weeks of UI paid by September 28, 2009

Weeks of UI paid by April 30, 2010

Implied weekly UI exit rate
Earnings during base year, in \$ (3)

\begin{tabular}{ccc}
35,335 & 36,905 & 48,994 \\
41.6 & 42.0 & 43.4 \\
387 & 392 & 442 \\
2.1 & 2.1 & 2.0 \\
$8.8 \%$ & $7.8 \%$ & $4.2 \%$ \\
$10.2 \%$ & $9.4 \%$ & $8.2 \%$ \\
$9.8 \%$ & $10.8 \%$ & $11.5 \%$ \\
$11.1 \%$ & $11.2 \%$ & $9.9 \%$ \\
$6.7 \%$ & $7.5 \%$ & $11.6 \%$ \\
$4.6 \%$ & $5.9 \%$ & $8.5 \%$ \\
$10.0 \%$ & $9.5 \%$ & $9.4 \%$ \\
25.3 & 25.3 & 25.4 \\
n.a & $5.2 \%$ & $4.8 \%$ \\
30.6 & 41.3 & 40.7 \\
n.a & 63.3 & 63.2 \\
n.a & $2.23 \%$ & $2.07 \%$ \\
\hline
\end{tabular}

Demographic data (used to create survey weights)
Female

Age: 24 or less

Age: $25-34$

Age: $35-44$

Age: $45-54$

Age: 55 or more

Race: \% white

Race: \% black

Race: \% other

Race: \% missing

Ethnicity: \% hispanic

Ethnicity: \% non-hispanic

Ethnicity: \% missing

Education: less than high school

Education: high school

Education: some college

Education: college

Cohort 1: 0-2 weeks of UI paid

Cohort 2: 10-12 weeks of UI paid

Cohort 3: 20-22 weeks of UI paid

Cohort 4: 30-32 weeks of UI paid

Cohort 5: 40-42 weeks of UI paid

Cohort 6: 50-53 weeks of UI paid

Cohort 7+: 60+ weeks of UI paid

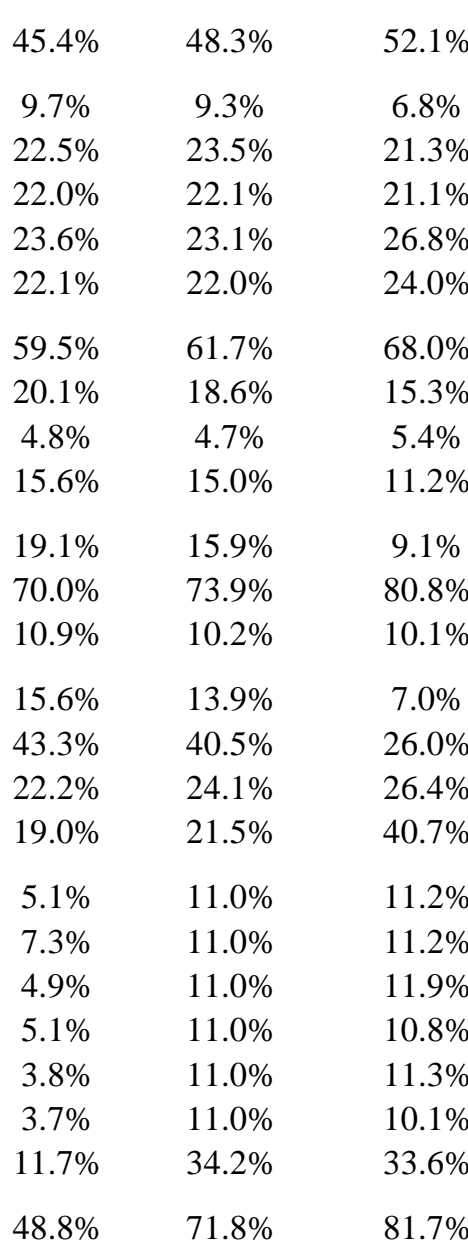

$52.1 \%$

$6.8 \%$

$21.3 \%$

$21.1 \%$

$26.8 \%$

$24.0 \%$

$68.0 \%$

$15.3 \%$

$5.4 \%$

$1.2 \%$

$9.1 \%$

$80.8 \%$

$10.1 \%$

$7.0 \%$

$26.0 \%$

$26.4 \%$

$40.7 \%$

$11.2 \%$

$11.2 \%$

$11.9 \%$

$10.8 \%$

$11.3 \%$

$10.1 \%$

$81.7 \%$

(1) The sample frame is weighted with strata weights, which adjust for the probability of being selected for the study.

(2) The respondents are weighted with sampling weights, which adjust for the probability of being selected for the study as well as non-response.

(3) The base earnings are top-coded at $\$ 99,999.99$. For top-coded earnings we imputed the mean above the top-code by assuming that base earnings follow a Pareto distribution. We estimated the two parameters of the Pareto distribution with the 90th percentile and the top-code (see Feenberg and Poterba, 1992, for details). 3.37\% of the unemployed workers in the universe have top-coded earnings and we estimated a mean above the top-code of \$152,191.

\begin{tabular}{cc}
\hline $45.5 \%$ & $47.2 \%$ \\
$10.1 \%$ & $10.4 \%$ \\
$23.1 \%$ & $25.5 \%$ \\
$22.2 \%$ & $21.8 \%$ \\
$23.4 \%$ & $23.8 \%$ \\
$21.3 \%$ & $18.5 \%$ \\
$58.9 \%$ & $59.8 \%$ \\
$20.8 \%$ & $20.0 \%$ \\
$4.7 \%$ & $4.5 \%$ \\
$15.6 \%$ & $15.8 \%$ \\
$18.8 \%$ & $17.8 \%$ \\
$70.1 \%$ & $70.4 \%$ \\
$11.1 \%$ & $11.8 \%$ \\
$15.9 \%$ & $14.1 \%$ \\
$43.2 \%$ & $45.1 \%$ \\
$21.9 \%$ & $22.1 \%$ \\
$19.0 \%$ & $18.7 \%$ \\
$16.9 \%$ & $17.9 \%$ \\
$19.7 \%$ & $19.1 \%$ \\
$16.8 \%$ & $16.6 \%$ \\
$15.8 \%$ & $15.7 \%$ \\
$11.2 \%$ & $10.9 \%$ \\
$8.0 \%$ & $8.1 \%$ \\
$11.7 \%$ & $11.8 \%$ \\
$48.8 \%$ & $48.7 \%$ \\
\hline &
\end{tabular}

\begin{tabular}{cc}
\hline 34,309 & 37,960 \\
41.0 & 41.2 \\
378 & 397 \\
2.1 & 2.3 \\
$8.7 \%$ & $5.6 \%$ \\
$9.6 \%$ & $8.6 \%$ \\
$10.8 \%$ & $10.8 \%$ \\
$10.8 \%$ & $12.4 \%$ \\
$6.4 \%$ & $7.6 \%$ \\
$4.4 \%$ & $5.7 \%$ \\
$9.9 \%$ & $10.4 \%$ \\
25.0 & 24.9 \\
$7.2 \%$ & $6.9 \%$ \\
27.5 & 27.4 \\
48.5 & 49.5 \\
$2.57 \%$ & $2.22 \%$ \\
\hline
\end{tabular}


Table 3.1a Linear regressions of time spent on job search (yesterday), with and without fixed effects

\begin{tabular}{|c|c|c|c|c|}
\hline $\begin{array}{l}\text { Dependent varialbe: } \\
\text { time spent on job search, in mins. per day }\end{array}$ & Week 1 & $\frac{\text { Pooled }}{\text { cross- }}$ & $\frac{\text { Fixed }}{\text { effects }}$ & $\frac{\text { Fixed }}{\text { effects }}$ \\
\hline Unemployment duration, in weeks & $\begin{array}{c}0.227 \\
(0.104)^{* *}\end{array}$ & $\begin{array}{l}-0.075 \\
(0.072)\end{array}$ & $\begin{array}{c}-2.73 \\
(0.250)^{* * *}\end{array}$ & $\begin{array}{c}-1.62 \\
(0.313)^{* * *}\end{array}$ \\
\hline Lapse (before November 8) & & & & $\begin{array}{c}-0.937 \\
(6.924)\end{array}$ \\
\hline Exhausted UI & & & & $\begin{array}{c}8.416 \\
(10.724)\end{array}$ \\
\hline After extension of November 8 & & & & $\begin{array}{c}-19.056 \\
(3.039)^{* * *}\end{array}$ \\
\hline Log(weekly benefit amount) & $\begin{array}{l}-19.303 \\
(12.570)\end{array}$ & $\begin{array}{c}-18.78 \\
(10.311)^{*}\end{array}$ & & \\
\hline Log(weekly previous wage) & $\begin{array}{l}10.781 \\
(7.284) \\
\end{array}$ & $\begin{array}{c}14.554 \\
(6.113)^{* *} \\
\end{array}$ & & \\
\hline Controlling for age, education, sex, race and ethnicity & $\mathrm{x}$ & $\mathrm{x}$ & & \\
\hline Dummies for day of week of diary & $\mathrm{x}$ & $\mathrm{x}$ & $\mathrm{x}$ & $\mathrm{x}$ \\
\hline Individual fixed effects & & & $\mathrm{x}$ & $\mathrm{x}$ \\
\hline Mean of dependent variable & 103.1 & 65.5 & 65.1 & 65.1 \\
\hline Min & 0 & 0 & 0 & 0 \\
\hline Max & 720 & 780 & 780 & 780 \\
\hline $\mathrm{N}$ & 3,924 & 24,366 & 25,180 & 25,180 \\
\hline R-squared & 0.10 & 0.05 & 0.66 & 0.67 \\
\hline
\end{tabular}

Robust standard errors in parentheses (clustered at individual level); ${ }^{*} \mathrm{p}<0.1,{ }^{*} \mathrm{p}<0.05, * * * \mathrm{p}<0.01$.

Notes: Survey weights are used. Universe: Unemployed; no job offer yet accepted; age 20-65.

Table 3.1b Linear regressions of time spent on job search (last 7 days), with and without fixed effects

\begin{tabular}{|c|c|c|c|c|}
\hline $\begin{array}{l}\text { Dependent varialbe: } \\
\text { time spent on job search, in mins. per day }\end{array}$ & $\underline{\text { Week } 1}$ & $\begin{array}{l}\text { Pooled } \\
\underline{\text { cross- }} \\
\underline{\text { section }} \\
\end{array}$ & $\frac{\text { Fixed }}{\text { effects }}$ & $\frac{\text { Fixed }}{\text { effects }}$ \\
\hline Unemployment duration, in weeks & $\begin{array}{c}0.093 \\
(0.130)\end{array}$ & $\begin{array}{c}0.059 \\
(0.134)\end{array}$ & $\begin{array}{c}-2.245 \\
(0.288)^{* * *}\end{array}$ & $\begin{array}{c}-1.538 \\
(0.331)^{* * *}\end{array}$ \\
\hline Lapse (before November 8) & & & & $\begin{array}{l}-1.096 \\
(7.994)\end{array}$ \\
\hline Exhausted UI & & & & $\begin{array}{l}-1.415 \\
(13.978)\end{array}$ \\
\hline After extension of November 8 & & & & $\begin{array}{c}-11.788 \\
(3.651)^{* * *}\end{array}$ \\
\hline Log(weekly benefit amount) & $\begin{array}{c}-2.921 \\
(16.950)\end{array}$ & $\begin{array}{c}-28.141 \\
(15.924)^{*}\end{array}$ & & \\
\hline Log(weekly previous wage) & $\begin{array}{c}18.855 \\
(10.931)^{*}\end{array}$ & $\begin{array}{c}38.659 \\
(10.370)^{* * *}\end{array}$ & & \\
\hline $\begin{array}{l}\text { Controlling for age, education, sex, race and ethnicity } \\
\text { Individual fixed effects }\end{array}$ & $\mathrm{x}$ & $\mathrm{x}$ & $\mathrm{x}$ & $\mathrm{x}$ \\
\hline Mean of dependent variable & 117.5 & 98.3 & 97.6 & 97.6 \\
\hline Min & 0 & 0 & 0 & 0 \\
\hline Max & 685.7 & 685.7 & 685.7 & 685.7 \\
\hline $\mathrm{N}$ & 3,983 & 24,638 & 25,449 & 25,449 \\
\hline R-squared & 0.04 & 0.05 & 0.77 & 0.77 \\
\hline
\end{tabular}

Robust standard errors in parentheses (clustered at individual level); ${ }^{*} \mathrm{p}<0.1,{ }^{* *} \mathrm{p}<0.05, * * * \mathrm{p}<0.01$.

Notes: Survey weights are used. Universe: Unemployed; no job offer yet accepted; age 20-65. 
Table 3.2 Linear regressions of time spent on job search (last 7 days), by job search method

\begin{tabular}{|c|c|c|c|c|c|c|c|c|c|c|}
\hline $\begin{array}{l}\text { Dependent variable: time spent } \\
\text { on job search, in mins. per day }\end{array}$ & Total & $\begin{array}{l}\text { Contacted } \\
\text { employer } \\
\text { directly }\end{array}$ & $\begin{array}{c}\text { Public } \\
\text { employment } \\
\text { agency }\end{array}$ & $\begin{array}{c}\text { Private } \\
\text { employment } \\
\text { agency }\end{array}$ & $\begin{array}{l}\text { Friends or } \\
\text { relatives }\end{array}$ & $\begin{array}{l}\text { Placed or } \\
\text { answered } \\
\quad \text { ads }\end{array}$ & $\begin{array}{l}\text { Went to } \\
\text { interview }\end{array}$ & $\begin{array}{c}\text { Sent out } \\
\text { resumes/ } \\
\text { applications }\end{array}$ & $\begin{array}{l}\text { Looked at } \\
\quad \text { ads }\end{array}$ & Other \\
\hline Unempl. duration, in weeks & $\begin{array}{c}-2.245 \\
(0.288)^{* * *} \\
\end{array}$ & $\begin{array}{c}-0.173 \\
(0.057)^{* * *} \\
\end{array}$ & $\begin{array}{c}0.006 \\
(0.038) \\
\end{array}$ & $\begin{array}{c}-0.093 \\
(0.040)^{* *}\end{array}$ & $\begin{array}{c}-0.182 \\
(0.061)^{* * *} \\
\end{array}$ & $\begin{array}{c}-0.352 \\
(0.080) * * * \\
\end{array}$ & $\begin{array}{l}-0.056 \\
(0.043) \\
\end{array}$ & $\begin{array}{c}-0.714 \\
(0.107)^{* * *}\end{array}$ & $\begin{array}{c}-0.378 \\
(0.099) * * *\end{array}$ & $\begin{array}{c}-0.303 \\
(0.079)^{* * *}\end{array}$ \\
\hline Individual fixed effects & $\mathrm{x}$ & $\mathrm{x}$ & $\mathrm{x}$ & $\mathrm{x}$ & $\mathrm{x}$ & $\mathrm{x}$ & $\mathrm{x}$ & $\mathrm{x}$ & $\mathrm{x}$ & $\mathrm{x}$ \\
\hline Mean of dependent variable & 97.6 & 7.6 & 3.3 & 3.6 & 9.0 & 13.4 & 3.2 & 23.0 & 26.6 & 8.0 \\
\hline Min & 0 & 0 & 0 & 0 & 0 & 0 & 0 & 0 & 0 & 0 \\
\hline Max & 685.7 & 385.7 & 300.0 & 257.1 & 428.6 & 428.6 & 435.0 & 514.3 & 515.7 & 685.7 \\
\hline $\mathrm{N}$ & 25,449 & 25,449 & 25,449 & 25,449 & 25,449 & 25,449 & 25,449 & 25,449 & 25,449 & 25,449 \\
\hline R-squared & 0.765 & 0.56 & 0.62 & 0.64 & 0.56 & 0.60 & 0.46 & 0.70 & 0.65 & 0.55 \\
\hline
\end{tabular}

Robust standard errors in parentheses (clustered at individual level); $* \mathrm{p}<0.1, * * \mathrm{p}<0.05, * * * \mathrm{p}<0.01$.

Notes: Survey weights are used. Universe: Unemployed; no job offer yet accepted; age 20-65. 
Table 4.1 Reservation wage ratio by duration of unemployment

\begin{tabular}{|c|c|c|c|c|c|c|c|c|}
\hline & $\underline{\text { All }} \underline{\underline{\text { durations }}}$ & 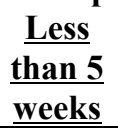 & $\frac{5-9}{\text { weeks }}$ & $\frac{10-14}{\underline{\text { weeks }}}$ & $\frac{15-19}{\underline{\text { weeks }}}$ & $\frac{20-24}{\underline{\text { weeks }}}$ & $\frac{25-49}{\underline{\text { weeks }}}$ & $\underline{\underline{50+}} \underline{\underline{\text { weeks }}}$ \\
\hline$\frac{\text { Feldstein \& Poterba (1984): }}{\text { All Job Losers and Leavers }}$ & 1.07 & 1.11 & 1.09 & 1.04 & 1.06 & 1.04 & 1.02 & 0.99 \\
\hline$\frac{\text { Feldstein \& Poterba (1984): }}{\text { Job Losers }}$ & 1.03 & 1.06 & 1.05 & 1.03 & 1.06 & 1.00 & 0.99 & 0.97 \\
\hline$\frac{\text { Krueger \& Mueller: }}{\text { Cross-section (1st week) }}$ & 0.99 & 1.04 & 1.02 & 1.01 & 1.00 & 1.06 & 0.95 & 0.94 \\
\hline$\frac{\text { Krueger \& Mueller: }}{\text { Longitudinal estimate }}$ & 0.99 & 1.00 & 1.00 & 1.00 & 0.99 & 0.99 & 0.98 & 0.97 \\
\hline
\end{tabular}

Note: Survey weights are used. Universe: Unemployed; no job offer yet accepted; age 20-65.

Feldstein and Poterba's (1984) estimates are from a sample of 2,228 unemployed from the May 1976 Current Population Survey. 
Table 4.2 Linear regressions of log reservation wage ratio on duration of unemployment, with and without fixed effects

\begin{tabular}{|c|c|c|c|c|c|c|c|c|c|c|}
\hline $\begin{array}{l}\text { Dependent variable: } \\
\text { log(reservation wage ratio) }\end{array}$ & Week 1 & $\begin{array}{l}\frac{\text { Pooled }}{\text { cross- }} \\
\underline{\text { section }}\end{array}$ & $\underline{\text { Fixed }}$ & $\underline{\text { Fixed }}$ & $\frac{\text { Savings }}{<\$ 10,000}$ & $\stackrel{\underline{\text { Savings }}}{>=\$ 10,000}$ & Age 20-50 & Age 51-65 & $\frac{\underline{\text { Savings }}}{\text { (age 20-50) }}$ & $\frac{\stackrel{\text { Savings }}{>=\$ 10,000}}{\text { (age 51-65) }}$ \\
\hline Unemployment duration, in weeks & $\begin{array}{c}-0.00127 \\
(0.00030)^{* * *}\end{array}$ & $\begin{array}{l}-0.00081 \\
(0.00040)^{* *}\end{array}$ & $\begin{array}{c}-0.00056 \\
(0.00056)\end{array}$ & $\begin{array}{r}-0.00042 \\
(0.00070)\end{array}$ & $\begin{array}{l}0.00014 \\
(0.00065)\end{array}$ & $\begin{array}{c}-0.00309 \\
(0.00114)^{* * *}\end{array}$ & $\begin{array}{l}0.00045 \\
(0.00072)\end{array}$ & $\begin{array}{c}-0.0026 \\
(0.00073)^{* * *}\end{array}$ & $\begin{array}{l}-0.00182 \\
(0.00159)\end{array}$ & $\begin{array}{c}-0.00423 \\
(0.00159)^{* * *}\end{array}$ \\
\hline Lapse (before November 8) & & & & $\begin{array}{l}0.018 \\
(0.015)\end{array}$ & & & & & & \\
\hline Exhausted UI & & & & $\begin{array}{r}-0.019 \\
(0.023)\end{array}$ & & & & & & \\
\hline After extension of November 8 & & & & $\begin{array}{l}0.0004 \\
(0.0064)\end{array}$ & & & & & & \\
\hline Log(weekly benefit amount) & $\begin{array}{c}-0.411 \\
(0.024)^{* * *}\end{array}$ & $\begin{array}{c}-0.426 \\
(0.027)^{* * *}\end{array}$ & & & & & & & & \\
\hline Log(weekly previous wage) & $\begin{array}{c}-0.131 \\
(0.037)^{* * *}\end{array}$ & $\begin{array}{l}-0.127 \\
(0.050)^{* *}\end{array}$ & & & & & & & & \\
\hline $\begin{array}{l}\text { Controlling for age, education, sex, race } \\
\text { and ethnicity }\end{array}$ & $\mathrm{x}$ & $\mathrm{x}$ & & & & & & & & \\
\hline $\begin{array}{l}\text { Dummies for unit of reported } \\
\text { reservation wage }\end{array}$ & $\mathrm{x}$ & $\mathrm{x}$ & $\mathrm{x}$ & $\mathrm{x}$ & $\mathrm{x}$ & $\mathrm{x}$ & $\mathrm{x}$ & $\mathrm{x}$ & $\mathrm{x}$ & $\mathrm{x}$ \\
\hline Individual fixed effects & & & $\mathrm{x}$ & $\mathrm{x}$ & $\mathrm{x}$ & $\mathrm{x}$ & $\mathrm{x}$ & $\mathrm{x}$ & $\mathrm{x}$ & $\mathrm{x}$ \\
\hline Mean of dependent variable & -0.076 & -0.107 & -0.105 & -0.105 & -0.057 & -0.276 & -0.054 & -0.249 & -0.225 & -0.339 \\
\hline Min & -1.107 & -1.107 & -1.107 & -1.107 & -1.107 & -1.107 & -1.107 & -1.107 & -1.107 & -1.077 \\
\hline Max & 1.099 & 1.099 & 1.099 & 1.099 & 1.099 & 1.087 & 1.099 & 1.094 & 1.087 & 1.084 \\
\hline $\mathrm{N}$ & 4,124 & 24,401 & 24,474 & 24,474 & 16,057 & 6,796 & 13,565 & 10,909 & 2,655 & 4,141 \\
\hline R-squared & 0.42 & 0.44 & 0.94 & 0.94 & 0.94 & 0.95 & 0.94 & 0.93 & 0.96 & 0.92 \\
\hline
\end{tabular}

Robust standard errors in parentheses(clustered at individual level); ${ }^{*} \mathrm{p}<0.1,{ }^{* *} \mathrm{p}<0.05, * * * \mathrm{p}<0.01$.

Notes: Survey weights are used. Universe: Unemployed; no job offer yet accepted; age 20-65. 
Table 4.3 Linear regressions of reservation commuting distance on duration of unemployment, with and without fixed effects

Dependent variable: Distance willing to commute, in min per day (for job paying the reservation wage)

Unemployment duration, in weeks

Lapse (before November 8)

Exhausted UI

After extension of November 8

\section{$\underline{\text { Week } 1} \underline{\text { Pooled cross- }} \underline{\underline{\text { Fixed effects }}} \underline{\text { Fixed effects }}$}

$\begin{array}{cccc}0.002 & 0.005 & 0.089 & 0.091 \\ (0.025) & (0.024) & (0.039)^{* *} & (0.046)^{* *}\end{array}$

1.417

(1.707)

$-0.278$

(1.537)

0.079

$(0.441)$

Controlling for age, education, sex, race, ethnicity, $\log$ (previous wage) and $\log ($ benefit $)$ $\mathrm{X}$ $\mathrm{X}$ Individual fixed effects

\begin{tabular}{|c|c|c|c|c|}
\hline Individual fixed effects & & & $\mathrm{X}$ & $\mathrm{X}$ \\
\hline Mean of dependent variable & 41.4 & 40.8 & 40.8 & 40.8 \\
\hline Min & 7.5 & 7.5 & 7.5 & 7.5 \\
\hline Max & 135.5 & 135.5 & 135.5 & 135.5 \\
\hline $\mathrm{N}$ & 4,369 & 26,126 & 26,995 & 26,995 \\
\hline R-squared & 0.10 & 0.14 & 0.90 & 0.90 \\
\hline
\end{tabular}

Notes: Survey weights are used. Universe: Unemployed; no job offer yet accepted; age 20-65.

Table 5.1 Job offers by type of work looking for (at time of the entry survey)

Looking for full-time job

Looking for part-time job

Doesn't matter

Not looking for work

Total

\begin{tabular}{c}
$\begin{array}{c}\text { \% of } \\
\text { total }\end{array}$ \\
\hline $75.1 \%$ \\
$4.3 \%$ \\
$16.7 \%$ \\
$3.9 \%$ \\
\hline
\end{tabular}

$3.9 \%$

$\%$

$\%$ received full-time $\%$ r offer

$15.6 \%$

$10.1 \%$

$14.0 \%$

$10.7 \%$

$14.9 \%$
$\%$ received full- or part-time offer

$20.9 \%$

$20.0 \%$

$17.5 \%$

$20.3 \%$

$6.5 \% \quad 20.5 \% \quad 6.0 \%$

$\%$ left UI early (but no job offer)

$10.0 \%$

$9.4 \%$

$7.6 \%$
$12.9 \%$

$4.9 \%$

$16.7 \%$

Notes: Survey weights are used. "Left UI early" is defined as those who left UI before they exhausted their UI benefits.

Universe: Respondents with at least two interviews in the baseline study. The sample size is 4,671. 
Table 5.2 Probit models (marginal effects) for leaving UI early and receiving a job offer

Dependent Variable:

Left UI early (before March 14, 2010)

\section{Explanatory Variables:}

Time spent on job search, in hours per week

$\log ($ reservation wage ratio)

Cohort 2

Cohort 3

Cohort 4

Cohort 5

Cohort 6

Cohort 7

Cohort 8

Recall expectation

With recall date

Age

$\mathrm{Age}^{\wedge} 2$

High school degree

Some college education

College degree

Some graduate education

Graduate degree

Black

Asian or other

Race not available

Hispanic

Ethnicity not available

Female

Married

Mean of dependent variable

\begin{tabular}{l} 
Min \\
Max \\
\hline $\mathrm{N}$
\end{tabular}

$\mathrm{N}$

Pseudo R-squared

Robust standard errors in parentheses; * $\mathrm{p}<0.1, * * \mathrm{p}<0.05, * * * \mathrm{p}<0.01$.

\begin{tabular}{|c|c|c|c|c|c|}
\hline (1) & (2) & (3) & (4) & (5) & (6) \\
\hline $\begin{array}{c}0.0018 \\
(0.0006)^{* * *}\end{array}$ & $\begin{array}{c}0.0018 \\
(0.0005)^{* * *}\end{array}$ & $\begin{array}{c}0.0017 \\
(0.0005)^{* * *}\end{array}$ & $\begin{array}{c}-0.0002 \\
(0.0007)\end{array}$ & $\begin{array}{c}-0.0002 \\
(0.0006)\end{array}$ & $\begin{array}{c}-0.0002 \\
(0.0006)\end{array}$ \\
\hline \multirow[t]{44}{*}{$\begin{array}{l}-0.0492 \\
(0.0255)^{*}\end{array}$} & $\begin{array}{l}-0.0485 \\
(0.0246)^{* *}\end{array}$ & $\begin{array}{l}-0.0517 \\
(0.0252)^{* *}\end{array}$ & & & \\
\hline & $\begin{array}{c}0.05 \\
(0.0352)\end{array}$ & $\begin{array}{l}0.0284 \\
(0.0331)\end{array}$ & & $\begin{array}{l}0.0372 \\
(0.0375)\end{array}$ & $\begin{array}{l}0.0388 \\
(0.0386)\end{array}$ \\
\hline & -0.0122 & -0.0155 & & -0.0181 & -0.0112 \\
\hline & & & & & \\
\hline & -0.0352 & -0.0393 & & -0.0119 & -0.0135 \\
\hline & $(0.0276)$ & $(0.0275)$ & & $(0.0313)$ & $(0.0312)$ \\
\hline & -0.0966 & -0.0912 & & 0.0343 & 0.0394 \\
\hline & $(0.0202)^{* * *}$ & $(0.0202)^{* * *}$ & & $(0.0371)$ & $(0.0371)$ \\
\hline & -0.0593 & -0.0544 & & 0.0015 & -0.0044 \\
\hline & $(0.0285)^{* *}$ & $(0.0287)^{*}$ & & $(0.0373)$ & $(0.0358)$ \\
\hline & -0.0991 & -0.0958 & & -0.0795 & -0.0767 \\
\hline & $(0.0204)^{* * *}$ & $(0.0204)^{* * *}$ & & $(0.0227)^{* * *}$ & $(0.0240)^{* * *}$ \\
\hline & -0.0872 & -0.0784 & & -0.0189 & -0.0078 \\
\hline & $(0.0196)^{* * *}$ & $(0.0207)^{* * *}$ & & $(0.0283)$ & $(0.0300)$ \\
\hline & & $\begin{array}{l}0.0003 \\
(0.0322)\end{array}$ & & & $\begin{array}{l}0.0508 \\
(0.0407)\end{array}$ \\
\hline & & 0.3872 & & & 0.0633 \\
\hline & & $(0.1533)^{* *}$ & & & $(0.1196)$ \\
\hline & & $\begin{array}{l}0.0012 \\
(0.0047)\end{array}$ & & & $\begin{array}{c}0.003 \\
(0.0052)\end{array}$ \\
\hline & & 0.000 & & & 0.000 \\
\hline & & $(0.0001)$ & & & $(0.0001)$ \\
\hline & & 0.0025 & & & 0.0312 \\
\hline & & $(0.0538)$ & & & $(0.0639)$ \\
\hline & & 0.0343 & & & 0.0799 \\
\hline & & $(0.0540)$ & & & $(0.0633)$ \\
\hline & & 0.1018 & & & 0.1185 \\
\hline & & $(0.0652)$ & & & $(0.0738)$ \\
\hline & & 0.0954 & & & 0.2085 \\
\hline & & $(0.0792)$ & & & $(0.1005)^{* *}$ \\
\hline & & 0.1356 & & & 0.0928 \\
\hline & & $(0.0773)^{*}$ & & & $(0.0776)$ \\
\hline & & -0.0055 & & & 0.0062 \\
\hline & & $(0.0241)$ & & & $(0.0263)$ \\
\hline & & 0.016 & & & 0.0007 \\
\hline & & $(0.0356)$ & & & $(0.0362)$ \\
\hline & & 0.0176 & & & 0.0786 \\
\hline & & $(0.0354)$ & & & $(0.0473)^{*}$ \\
\hline & & -0.0106 & & & 0.0195 \\
\hline & & $(0.0306)$ & & & $(0.0381)$ \\
\hline & & -0.0037 & & & -0.0831 \\
\hline & & $(0.0305)$ & & & $(0.0238)^{* * *}$ \\
\hline & & 0.0109 & & & -0.0051 \\
\hline & & $(0.0180)$ & & & $(0.0187)$ \\
\hline & & 0.0363 & & & 0.0092 \\
\hline & & $(0.0199)^{*}$ & & & $(0.0231)$ \\
\hline 0.1653 & 0.1653 & 0.1649 & 0.1611 & 0.1611 & 0.1614 \\
\hline 0 & 0 & 0 & 0 & 0 & 0 \\
\hline 1 & 1 & 1 & 1 & 1 & 1 \\
\hline 4,433 & 4,433 & 4,382 & 3,918 & 3,918 & 3,864 \\
\hline 0.0084 & 0.0348 & 0.0589 & 0.000 & 0.0077 & 0.0313 \\
\hline
\end{tabular}

Notes: Survey weights are used. Sample: unemployed; no job offer yet accepted. For the job offer regressions, only respondents with two or more interviews were included.

\section{Received job offer}


Table 6.1a Hourly offered wage below and above hourly reservation wage

Hourly offered wage $<$

Hourly offered wage $>=$

hourly reservation wage

hourly reservation wage

\begin{tabular}{lcc}
\hline Accepted & $50.5 \%$ & $74.1 \%$ \\
Not accepted & $23.6 \%$ & $10.3 \%$ \\
Undecided & $25.9 \%$ & $15.7 \%$ \\
\hline $\mathrm{N}$ & 566 & 587 \\
\hline
\end{tabular}

Table 6.1b Hourly offered wage below and above hourly reservation wage (full time offers only)

Hourly offered wage $<$

hourly reservation wage

Hourly offered wage $>=$

hourly reservation wage

\begin{tabular}{lcc}
\hline Accepted & $44.4 \%$ & $73.8 \%$ \\
Not accepted & $24.2 \%$ & $11.4 \%$ \\
Undecided & $31.4 \%$ & $14.8 \%$ \\
\hline $\mathrm{N}$ & 361 & 417 \\
\hline
\end{tabular}


Table 6.2 Marginal effects from probit model for accepting a job offer, conditional on receiving an offer

\begin{tabular}{|c|c|c|c|c|}
\hline & (1) & (2) & (3) & (4) \\
\hline Hourly offered wage $\geq$ Hourly reservation wage (lagged) & $\begin{array}{c}0.212 \\
(0.098)^{* *}\end{array}$ & & $\begin{array}{c}0.196 \\
(0.061)^{* * *}\end{array}$ & $\begin{array}{c}0.206 \\
(0.095)^{* *}\end{array}$ \\
\hline $\begin{array}{l}\text { Hourly offered wage } \geq \text { Hourly reservation wage (lagged) } \\
* \text { Part time job offer }\end{array}$ & $\begin{array}{l}-0.215 \\
(0.127)^{*}\end{array}$ & & & $\begin{array}{l}-0.209 \\
(0.126)^{*}\end{array}$ \\
\hline Hourly offered wage $\geq$ Hourly previous wage & & $\begin{array}{l}0.152 \\
(0.101)\end{array}$ & $\begin{array}{l}0.106 \\
(0.070)\end{array}$ & \\
\hline $\begin{array}{l}\text { Hourly offered wage } \geq \text { Hourly previous wage } \\
* \text { Parttime job offer }\end{array}$ & & $\begin{array}{r}-0.055 \\
(0.126)\end{array}$ & & \\
\hline Parttime job offer & $\begin{array}{c}0.21 \\
(0.079)^{* * *}\end{array}$ & $\begin{array}{c}0.152 \\
(0.079)^{*}\end{array}$ & & $\begin{array}{c}0.207 \\
(0.080)^{* * *}\end{array}$ \\
\hline Log(lagged hourly reservation wage) & $\begin{array}{l}-0.109 \\
(0.122)\end{array}$ & & & $\begin{array}{l}-0.104 \\
(0.127)\end{array}$ \\
\hline Log(hourly offered wage) & $\begin{array}{l}0.216 \\
(0.108)^{* *}\end{array}$ & $\begin{array}{c}0.185 \\
(0.091)^{* *}\end{array}$ & & $\begin{array}{c}0.222 \\
(0.107)^{* *}\end{array}$ \\
\hline Log(hourly previous wage) & & $\begin{array}{c}-0.029 \\
(0.098)\end{array}$ & & \\
\hline
\end{tabular}

$\begin{array}{ll}\text { Savings }<\$ 10,000 & 0.013\end{array}$

$(0.088)$

$\begin{array}{ll}\text { Unemployment duration, in weeks } & 0.001\end{array}$

\begin{tabular}{|c|c|c|c|c|}
\hline & & & & $(0.001)$ \\
\hline Mean of dependent variable & 0.61 & 0.61 & 0.61 & 0.61 \\
\hline Min & 0 & 0 & 0 & 0 \\
\hline Max & 1 & 1 & 1 & 1 \\
\hline $\mathrm{N}$ & 1,153 & 1,153 & 1,153 & 1,153 \\
\hline Pseudo R-squared & 0.07 & 0.05 & 0.05 & 0.07 \\
\hline
\end{tabular}

Notes: Survey weights are used. Sample: Respondents age 20-65. 
Table 6.3 Probit models (marginal effects) for accepting a job offer that is below the reservation wage

Explanatory Variable

Unemployment duration: 27 - 52 weeks

Unemployment duration: 53 - 78 weeks

Unemployment duration: 79 weeks and more

Weeks since reservation wage reported

Part-time job offer

Risk taker

Incentive choice: $\$ 40$

Initial savings less than $\$ 10,000$

Age / 10

$\operatorname{Age}^{\wedge} 2 / 100$

Some college education

College degree

Some graduate education

Graduate degree

Female

Married

Female*married

Black

Asian or other race

Race not available

Hispanic

Ethnicity not available

Mean of dependent variable

$\mathrm{N}$

Pseudo R-squared
Full-time offers only

\begin{tabular}{cc}
\multicolumn{2}{c}{ Full-time offers only } \\
\hline 0.102 & 0.098 \\
$(0.128)$ & $(0.127)$ \\
-0.042 & -0.053 \\
$(0.131)$ & $(0.134)$ \\
0.302 & 0.314 \\
$(0.124)^{* *}$ & $(0.123)^{* *}$ \\
-0.019 & -0.013 \\
$(0.043)$ & $(0.042)$
\end{tabular}

$-0.215$

$(0.119)^{*}$

0.086

(0.102)

0.121

(0.126)

0.147

(0.362)

$-0.023$

(0.043)

0.114

(0.162)

0.241

(0.176)

0.062

(0.228)

0.301

$(0.175)^{*}$

0.147

(0.158)

$-0.022$

(0.166)

$-0.253$

(0.206)

$-0.255$

$(0.118)^{* *}$

$-0.192$

(0.217)

$-0.127$

(0.172)

0.047

(0.159)

0.453

$(0.159)^{* * *}$

$-0.060$

(0.386)

0.000

(0.046)

0.146

(0.159)

0.315

$(0.159)^{* *}$

0.127

(0.216)

0.342

$(0.175)^{*}$

0.126

(0.156)

0.043

(0.154)

$-0.260$

(0.198)

$-0.266$

$(0.119)^{* *}$

$-0.233$

(0.223)

$-0.128$

(0.174)

$-0.008$

(0.146)

0.454

$(0.163)^{* * *}$

0.447

361

359

0.119

0.143

All offers

$0.083 \quad 0.074$

(0.110) (0.110)

$0.055 \quad 0.028$

(0.113) (0.116)

$0.264 \quad 0.265$

$(0.097)^{* * *} \quad(0.104)^{* *}$

$-0.052-0.052$

$(0.027)^{*} \quad(0.027)^{* *}$

$0.222 \quad 0.204$

$(0.087)^{* *} \quad(0.086)^{* *}$

$-0.191$

$(0.090)^{* * *}$

$-0.082$

(0.086)

$-0.003$

(0.113)

$0.251 \quad 0.179$

(0.304) (0.306)

$-0.035 \quad-0.027$

$(0.035) \quad(0.035)$

$-0.030 \quad-0.026$

(0.121) (0.121)

$0.154 \quad 0.192$

(0.135) (0.133)

$\begin{array}{ll}-0.026 & 0.037\end{array}$

(0.170) (0.167)

$0.273 \quad 0.275$

$(0.142)^{*} \quad(0.146)^{*}$

$0.123 \quad 0.080$

$\begin{array}{ll}(0.131) & (0.129)\end{array}$

$-0.047 \quad-0.030$

(0.149) (0.147)

$-0.257 \quad-0.252$

$(0.176) \quad(0.175)$

$-0.154 \quad-0.131$

(0.104) (0.108)

$-0.224 \quad-0.253$

(0.211) (0.216)

$0.056 \quad 0.065$

(0.171) (0.174)

$-0.062 \quad-0.075$

(0.141) (0.137)

$0.347 \quad 0.326$

$(0.140)^{* * *}$

$(0.149)^{* *}$

Notes: Robust standard errors in parentheses (clustered at individual level); $* \mathrm{p}<0.1, * * \mathrm{p}<0.05, * * * \mathrm{p}<0.01$. 